\title{
PINS Measurements of Explosive Simulants for Cargo Screening
}

\author{
E. H. Seabury
}

June 2008



The INL is a U.S. Department of Energy National Laboratory operated by Battelle Energy Alliance 
INL/EXT-08-14053

\title{
PINS Measurements of Explosive Simulants for Cargo Screening
}

\author{
E. H. Seabury
}

June 2008

\section{Idaho National Laboratory \\ Idaho Falls, Idaho 83415}

http://www.inl.gov

Prepared for the

Battelle Memorial Institute and for the

U.S. Department of Energy

Under DOE Idaho Operations Office

Contract DE-AC07-05ID14517 


\section{Disclaimer}

This report was prepared as an account of work sponsored by an agency of the United States Government. Neither the United States Government nor any agency thereof, nor any of their employees, makes any warranty, express or implied, or assumes any legal liability or responsibility for the accuracy, completeness, or usefulness of any information, apparatus, product or process disclosed, or represents that its use would not infringe privately owned rights. References herein to any specific commercial product, process, or service by trade name, trademark, manufacturer, or otherwise, does not necessarily constitute or imply its endorsement, recommendation, or favoring by the United States Government or any agency thereof. The views and opinions of authors expressed herein do not necessarily state or reflect those of the United States Government or any agency thereof. 


\section{CONTENTS}

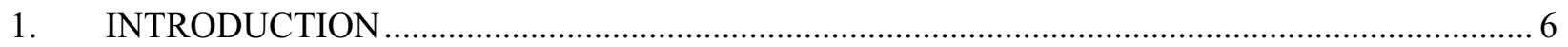



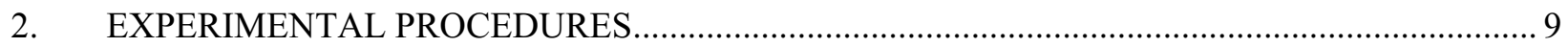

2.1 Californium neutron source-based system …................................................................ 9



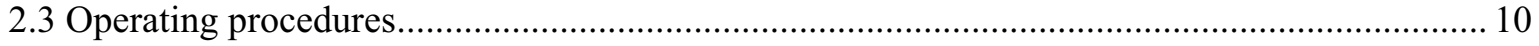

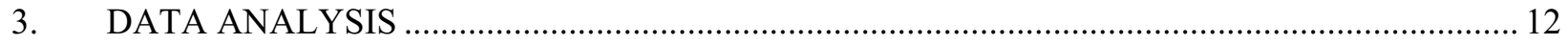



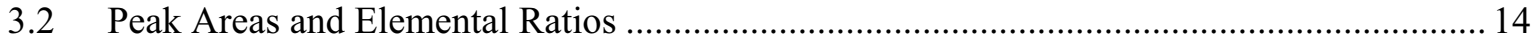



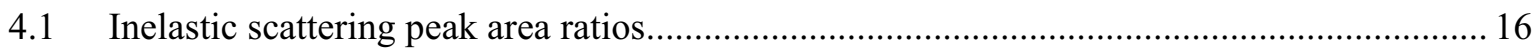

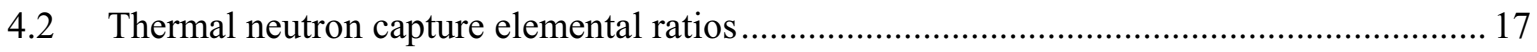

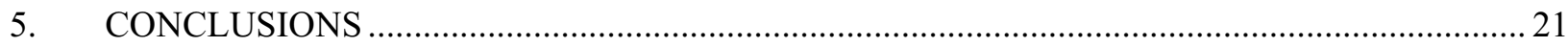

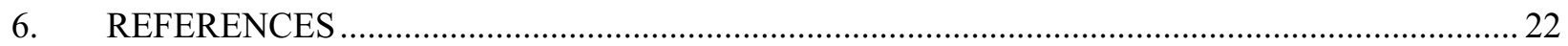

Appendix A-Peak Area Tables 


\section{FIGURES}

Figure 1. Californium-252, deuterium-deuterium (DD) fusion, and deuterium-tritium (DT) fusion neutron spectra.



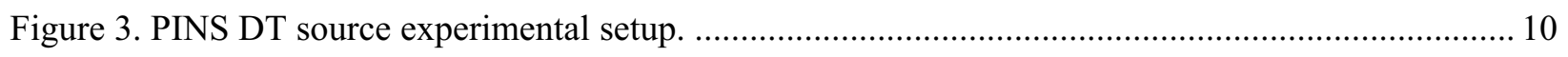

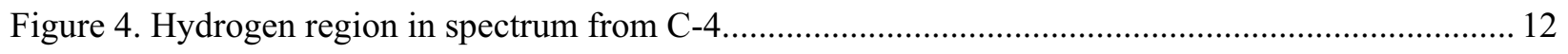



Figure 6. Hydrogen region in spectrum from C-4 after background subtraction.................................... 14

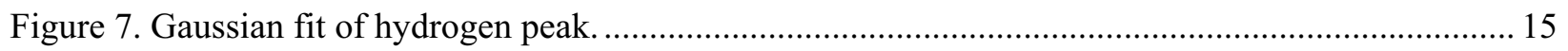

Figure 8. Hydrogen region in Red Dot explosive and simulant spectra. ............................................... 19

Figure 9. Oxygen region in Red Dot explosive and simulant spectra.................................................. 20

Figure 10. Nitrogen region in Red Dot explosive and simulant spectra. .............................................. 20

Figure B1. Hydrogen region of black powder explosive and simulant spectrat ...................................... 2

Figure B2. Oxygen region of black powder explosive and simulant spectra........................................ 3

Figure B3. Nitrogen region of black powder explosive and simulant spectra. …................................... 3

Figure B4. Hydrogen region of C-4 explosive and simulant spectra..................................................... 4

Figure B5. Oxygen region of C-4 explosive and simulant spectra ….............................................. 4

Figure B6. Nitrogen region of C-4 explosive and simulant spectra.................................................. 5

Figure B7. Hydrogen region of Detasheet explosive and simulant spectra. .......................................... 5

Figure B8. Oxygen region of Detasheet explosive and simulant spectra.............................................5

Figure B9. Nitrogen region of Detasheet explosive and simulant spectra. .......................................... 6 
Figure B10. Hydrogen region of Detagel explosive and Blastrite-3 simulant spectra............................ 6

Figure B11. Oxygen region of Detagel explosive and Blastrite-3 simulant spectra............................... 7

Figure B12. Nitrogen region of Detagel explosive and Blastrite-3 simulant spectra. …........................ 7

Figure B13. Hydrogen region of Red Dot explosive and simulant spectra........................................... 8

Figure B14. Oxygen region of Red Dot explosive and simulant spectra........................................... 8

Figure B15. Nitrogen region of Red Dot explosive and simulant spectra. ............................................ 9

Figure B16. Hydrogen region of Semtex 1-A explosive and simulant spectra..................................... 9

Figure B17. Oxygen region of Semtex 1-A explosive and simulant spectra. ....................................... 10

Figure B18. Nitrogen region of Semtex 1-A explosive and simulant spectra....................................... 10

Figure B19. Hydrogen region of TNT explosive and simulant spectra. .............................................. 11

Figure B20. Oxygen region of TNT explosive and simulant spectra. ............................................... 11

Figure B21. Nitrogen region of TNT explosive and simulant spectra................................................. 12

Figure B22. Hydrogen region of Z-Powder explosive and simulant spectra. ....................................... 12

Figure B23. Carbon region of Z-Powder explosive and simulant spectra. .......................................... 13

Figure B24. Nitrogen region of Z-Powder explosive and simulant spectra......................................... 13 


\section{PINS Measurements of Explosive Simulants for Cargo Screening}

\section{INTRODUCTION}

As part of its efforts to prevent the introduction of explosive threats on commercial flights, the Transportation Security Administration (TSL) is evaluating new explosives detection systems (EDSs) for use in air cargo inspection. The TSL has contracted Battelle to develop a new type of explosives simulant to assist in this development. These are designed to mimic the elemental profile $(\mathrm{C}, \mathrm{H}, \mathrm{N}, \mathrm{O}$, etc.) of explosives as well as their densities. Several "neutron in-gamma out" $(n, \gamma)$ techniques have been considered to quantify the elemental profile in these new simulants and the respective explosives. The method chosen by Battelle is Portable Isotopic Neutron Spectroscopy (PINS) [1], developed by Idaho National Laboratory (INL). Battelle wishes to validate that the simulants behave like the explosive threats with this technology.

Presently, most interrogation of aircraft luggage for bulk explosives is performed with Xray and computed tomography (CT) systems. However, cargo inspection requires the greater penetrating power neutrons or high-energy gamma rays. A variety of high energy photon and $(n, \gamma)$ techniques have been utilized to detect explosives in different settings, aircraft cargo being perhaps the most challenging. Existing X-ray and CT explosives simulants do not match the overall chemical profile (percent $\mathrm{C}, \mathrm{H}, \mathrm{N}, \mathrm{O}$, etc.) of explosives. They often contain extraneous materials (e.g. $\mathrm{Fe}_{2} \mathrm{O}_{3}, \mathrm{SiO}_{2}$, and $\mathrm{B}_{4} \mathrm{C}$ ) in order to adjust $\mathrm{CT}$ number, Effective Average Atomic Number ( $Z_{\text {eff }}$ ), and density. Many of these added elements ( $\mathrm{Fe}, \mathrm{Si}$, and B) are not found in explosives. Hence these older explosives simulants are not suitable for neutron or gamma-ray techniques. Their presence may introduce artifacts into the spectrum obtained and could potentially interfere with proper interrogation. Hence there is a need for new simulants to assist the development of neutron- and gamma-based technologies for explosives interrogation. To address this situation Battelle has developed a series of explosives simulants. Battelle initially contracted Van Aken Technologies to develop such a line of explosives simulants. Battelle later developed their own line of explosives simulants using different materials. 


\subsection{Neutron sources and neutron-induced reactions}

Gammas rays are produced primarily through two neutron interactions on atomic nuclei. One of these reactions is thermal neutron capture. In this reaction, a low-energy, slow neutron is captured by an atomic nucleus which then immediately emits one or more gamma rays. A second reaction occurs when a more energetic neutron inelastically scatters off of an atomic nucleus, which is left in an excited state. The nucleus then de-excites by gamma-ray emission. The choice of a neutron source in an interrogation system depends on whether thermal capture, inelastic scattering, or both are necessary to observe all of the elements of interest.

Explosives consist primarily of the elements carbon, oxygen, nitrogen, and hydrogen. The elemental capture cross sections for carbon and oxygen are 0.0035 barns and 0.00019 barns respectively. The elemental capture cross sections for hydrogen and nitrogen are 0.33 and 0.0795 barns respectively. Carbon and oxygen seldom react with thermal neutrons and are more likely to react with higher energy neutrons through neutron inelastic scattering. This requires neutrons of energy at least $4.4 \mathrm{MeV}$ in the case of the carbon and $6.13 \mathrm{MeV}$ in the case of oxygen. Hydrogen nuclei cannot be excited by inelastic scattering and can only be detected through thermal neutron capture. The identification of explosives requires both thermal neutrons and neutrons exceeding $6.13 \mathrm{MeV}$ in energy.

The energy distributions of three common neutron sources are shown in Figure 1. The PINS system usually uses a Californium-252 source to interrogate suspected chemical warfare materiel (CWM). CWM consists of a variety of elements of interest and the large energy distribution of neutrons from ${ }^{252} \mathrm{Cf}$ spontaneous fission allows excitation of many of these atomic nuclei. Carbon and oxygen are not generally observed in the spectra from ${ }^{252} \mathrm{Cf}$ based interrogation however. This is due to the relatively low number of higher-energy neutrons produced in ${ }^{252} \mathrm{Cf}$ fission. Similarly, the $2.5 \mathrm{MeV}$ neutrons produced in a deuterium-deuterium (DD) neutron generator are too low in energy to excite carbon and oxygen.

In order to readily excite carbon and oxygen nuclei, a deuterium-tritium (DT) neutron generator is used. The DT neutron generator consists of a small particle accelerator with target. The particle beam consists of deuterium and tritium ions, which then impinge on a target previously impregnated with deuterium and tritium. Some of these nuclei undergo the fusion reaction below

$$
\mathrm{D}+\mathrm{T} \rightarrow{ }^{4} \mathrm{He}+\mathrm{n}
$$

resulting in the production of an alpha particle and a neutron of about $14 \mathrm{MeV}$ in energy. These neutrons readily excite carbon and oxygen nuclei through inelastic scattering. Thermal neutrons are available from some of these higher-energy neutrons slowing down or moderating in surrounding materials and in the test item itself. 




Figure 1. Californium-252, deuterium-deuterium (DD) fusion, and deuterium-tritium (DT) fusion neutron spectra. 


\section{EXPERIMENTAL PROCEDURES}

The experimental arrangement for measuring both the explosive simulants and their respective explosives was simple, consisting of only one detector, a neutron source, and appropriate shielding. Because the simulants were of relatively small masses for neutron interrogation, they were assessed with both a neutron generator-based and a ${ }^{252} \mathrm{Cf}$-based system. This was in order to provide adequate hydrogen and nitrogen excitation without relying heavily on moderation of neutrons within the test samples themselves.

\subsection{Californium neutron source-based system}

The Cf-based PINS system was operated with a $9.4 \mu \mathrm{g}{ }^{252} \mathrm{Cf}$ neutron source, producing approximately 20 million neutrons per second. Gamma rays were detected with a high-purity germanium (HPGe) detector of approximately $45 \%$ relative efficiency. The HPGe detector was shielded from direct view of the neutron source by two $4 \times 4 \times 2$ inch blocks of tungsten, and a bismuth collimator shielded the detector from background gamma rays produced by neutron interactions in the floor. The ${ }^{252} \mathrm{Cf}$ source experimental setup is depicted schematically in Figure 2.

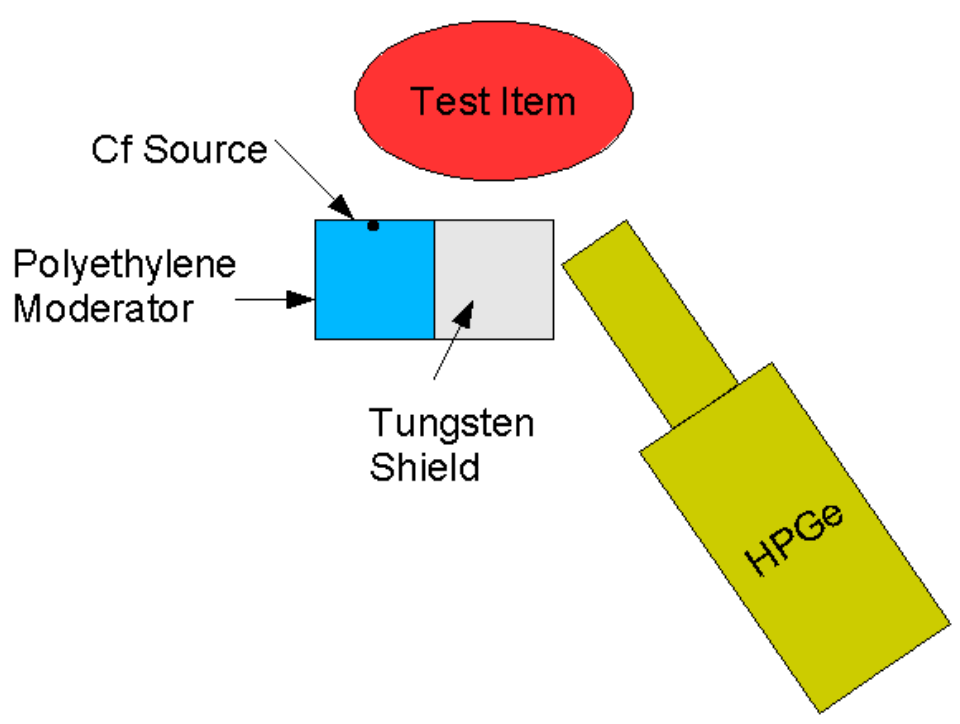

Figure 2. PINS ${ }^{252} \mathrm{Cf}$ source experimental setup. 


\subsection{DT neutron generator-based system.}

A DT neutron generator was used as the neutron source for these experiments. The neutron generator can produce approximately $1 \mathrm{E}+08 \mathrm{n} / \mathrm{s}$, but was operated at an output of approximately $3 \mathrm{E}+07 \mathrm{n} / \mathrm{s}$ In order to reduce the dead time on the data acquisition electronics for the HPGe. The experimental arrangement can be seen in Figure 3 below. The neutron generator was placed in a polyethylene moderator block and the detector was shielded from direct view of the generator and polyethylene by lead bricks. The detector was also shielded from below and above by lead bricks to minimize detection of gamma rays from materials surrounding the experimental setup.

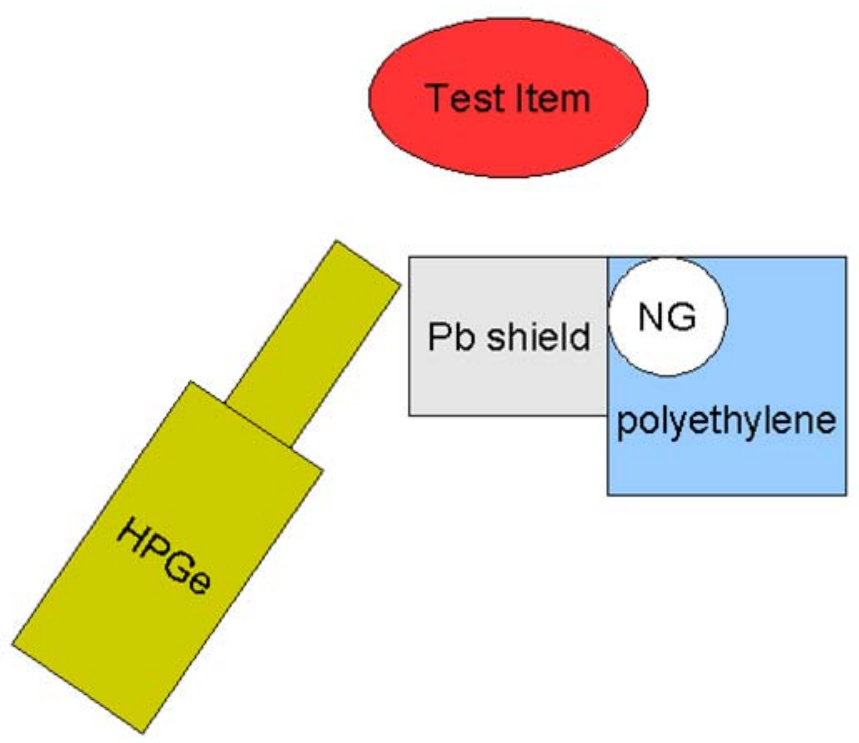

Figure 3. PINS DT source experimental setup.

\subsection{Operating procedures}

For both setups a background spectrum was measured at the beginning of each day. These spectra were used to subtract the portion of the gamma spectrum for a test item that was due to the surrounding materials. Test items were placed in front of the systems and spectra were measured, with intermediate spectra being saved every 1000 live seconds. Replicate measurements of a particular test item were made by stopping the data acquisition, removing or turning off the neutron source, and finally removing and then either replacing the test item or substituting a new one. This resulted in slight geometry changes between replicate measurements. 
The explosive simulants for C-4, Semtex 1-A, Detasheet, Black Powder. Z-powder, Blastrite-3, Red Dot, and TNT were all measured with both the ${ }^{252} \mathrm{Cf}$ based system as well as with the neutron generator system. These measurements occurred at the PINS laboratory in Idaho Falls, ID. The measurements of actual explosives were performed only with the DT generator-based system at the PBF facility of Idaho National Laboratory. ${ }^{252} \mathrm{Cf}$ is presently unavailable at the PBF facility where live explosives can be used.

The simulants were all of relatively small mass, on the order of $1 \mathrm{~kg}$ of test material, whereas much larger masses of explosives were used. The explosives masses were on the order of $5 \mathrm{~kg}$ or more in order to obtain better statistics and more thermal neutron flux within the explosive iteself. The only exception to this was the Semtex-1A. There was only approximately $1 \mathrm{~kg}$ of this explosive available at INL for testing, comprised of a collection of smaller masses on the order of 50-200 grams. 


\section{DATA ANALYSIS}

The data for these measurements consisted of gamma-ray spectra for each of the simulants and each of their respective explosives. The spectra were examined for peaks of specific energies, characteristic of particular elements. For example, Figure 4 below shows a segment of the gamma-ray spectrum for C-4. In the spectrum, the $2223 \mathrm{keV}$ peak from thermal neutron capture on hydrogen can be clearly seen. Other peaks of interest are the $6129 \mathrm{keV}$ peak from inelastic scattering off ${ }^{16} \mathrm{O}$, the $10.8 \mathrm{Mev}$ peak from thermal neutron capture on ${ }^{14} \mathrm{~N}$, and the $4439 \mathrm{keV}$ peak from inelastic scattering off ${ }^{12} \mathrm{C}$. The $4439 \mathrm{keV}$ peak is shown in Figure 5. This peak is much broader than others of similar energy due to Doppler broadening of the gamma ray. A final peak of interest in these measurements was the $2230 \mathrm{keV}$ peak from inelastic scattering off ${ }^{32} \mathrm{~S}$ and the $2813 \mathrm{keV}$ peak from inelastic scattering off ${ }^{39} \mathrm{~K}$.

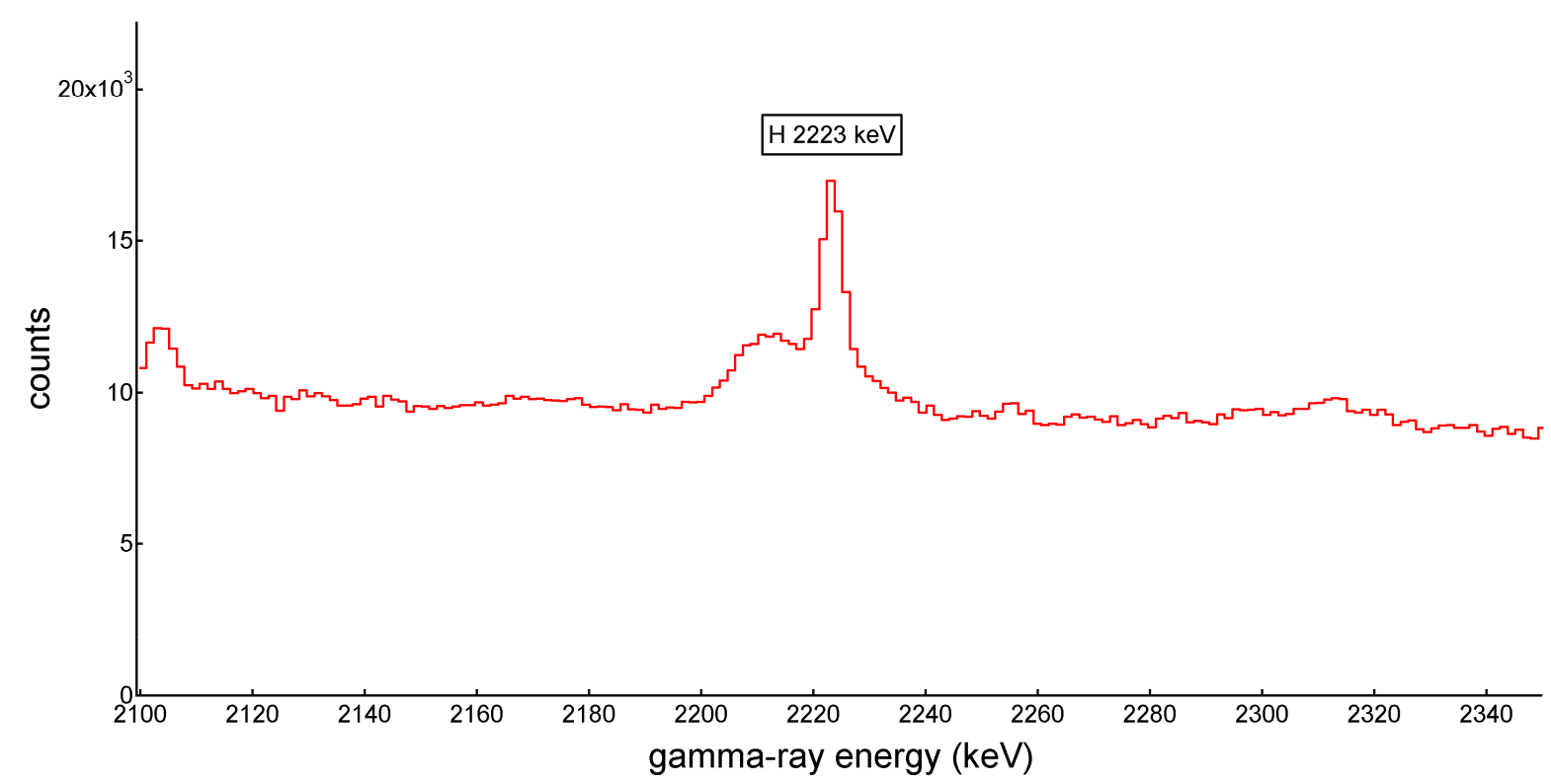

Figure 4. Hydrogen region in spectrum from C-4. 


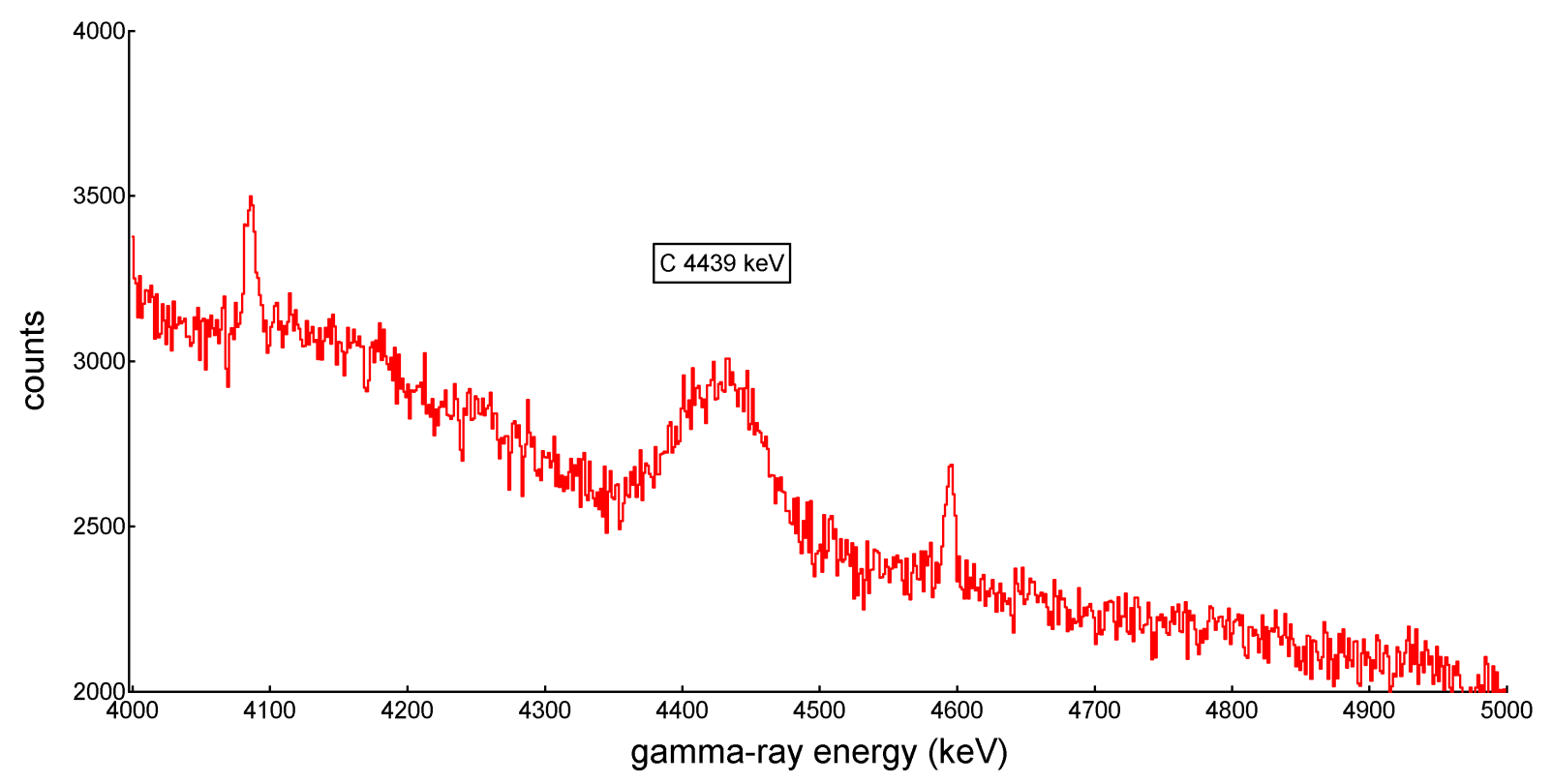

Figure 5. Carbon region in spectrum from C-4.

In addition to examining the spectra for the expected peaks from the elements comprising explosives, the spectra from the simulants were examined for additional peaks from elements not expected to be in explosives, such as B, Fe, and Si.

\subsection{Background Subtraction}

In order to determine the areas of peaks of interest, the background spectra had first to be subtracted from those of the test items. These background spectra were of a shorter measurement time than those of either the simulants or explosives. The neutron generator output does vary somewhat over time and the appropriate multiple of the background spectrum to subtract cannot be accurately determined by the ratio of measurement times. Instead the area of a peak in the spectrum that is not expected to be due to the test item is used to determine the correct ratio of background to foreground spectra. In these measurements, the $2614 \mathrm{keV}$ peak from inelastic scattering off lead was used. This gamma ray is expected to be due entirely to the shielding material surrounding the detector, and therefore a good measure of the total neutron generator output during the counting time. Figure 6 shows the hydrogen region of the same spectrum shown in Figure 4 after background subtraction. As can be seen in the figure, the large multiplet of peaks to the left of the hydrogen peak is largely removed after subtraction. This multiplet is due to neutron interactions on the detector itself. Similarly, gamma rays from interactions on the floor or shielding material are also largely removed in the subtraction. 


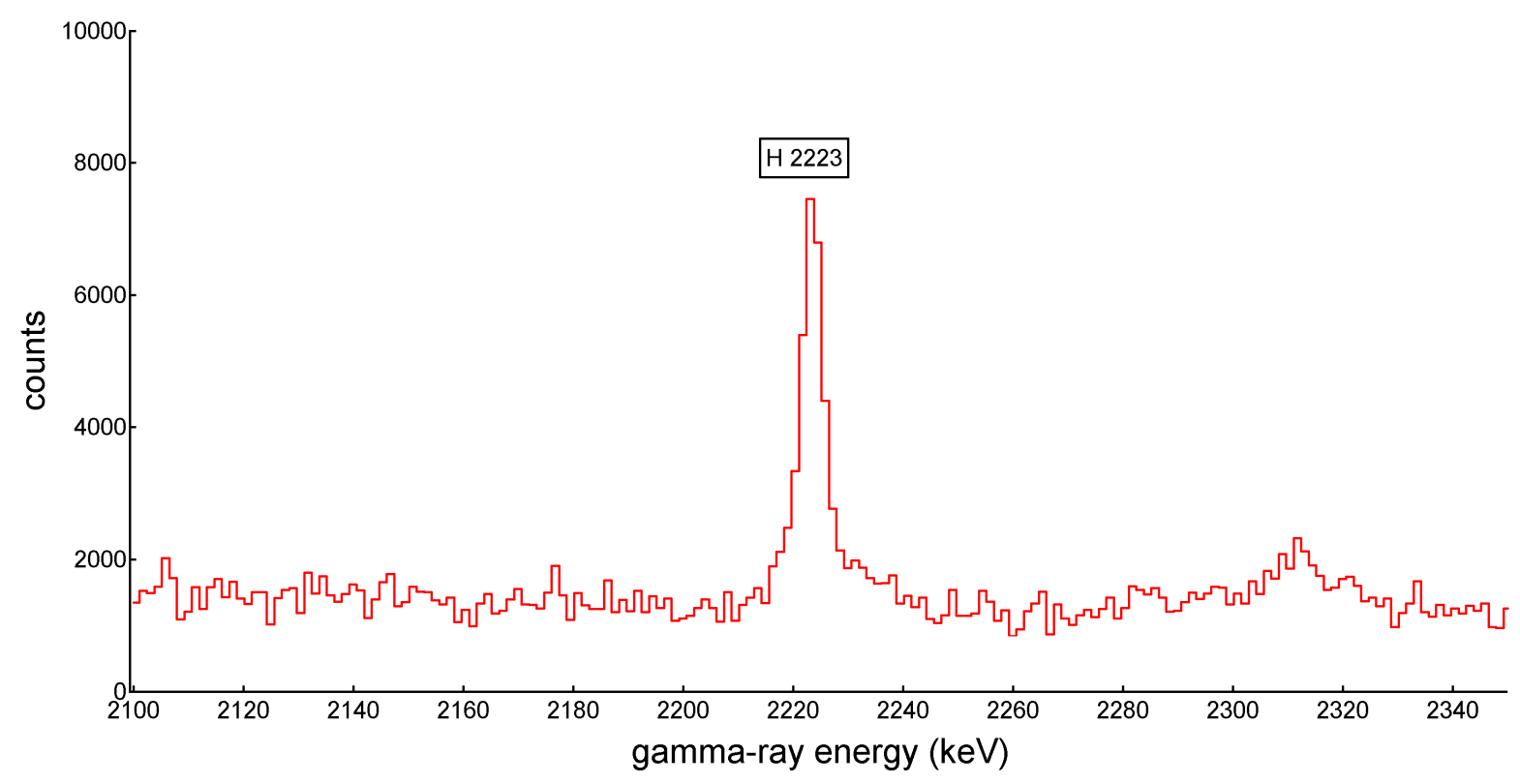

Figure 6. Hydrogen region in spectrum from C-4 after background subtraction.

\subsection{Peak Areas and Elemental Ratios}

Peak areas are determined, after background subtraction, by fitting a peak or set of peaks with gaussian curves over a flat background. The Gauss program, developed at INL [2], was used to fit peaks. A sample screenshot from the program is shown in Figure 7, where the same peak from thermal neutron capture on hydrogen is fit with a set of gaussian curves. The peak areas, full widths at half maximum, and uncertainties are reported by the program. The peaks due to neutron interactions on carbon, oxygen, hydrogen, and sulfur were fit in this manner. Nitrogen peak areas were determined differently.

Nitrogen reacts very weakly with fast neutron and weakly with thermal neutrons. The gamma ray peak of interest from thermal neutron capture on nitrogen has an energy of 10.8 $\mathrm{MeV}$. The HPGe detector is inefficient at detecting gamma rays of such high energy, and nitrogen peaks in the explosive and simulant spectra are rarely able to be fit with gaussians due to the poor statistics. Instead, a summing process is used. A nine-channel wide region of the spectrum where the nitrogen peak is expected to be from the energy calibration is summed, as well as separate sums of forty-channel wide regions both higher and lower in energy. The higher and lower energy regions provide the background counts to be subtracted from the nitrogen region. The normalized difference provides the net nitrogen counts. This procedure is also performed on the first escape peak of the nitrogen $10.8 \mathrm{MeV}$ peak in order to obtain better statistics. From the peak areas, elemental ratios can be determined. 


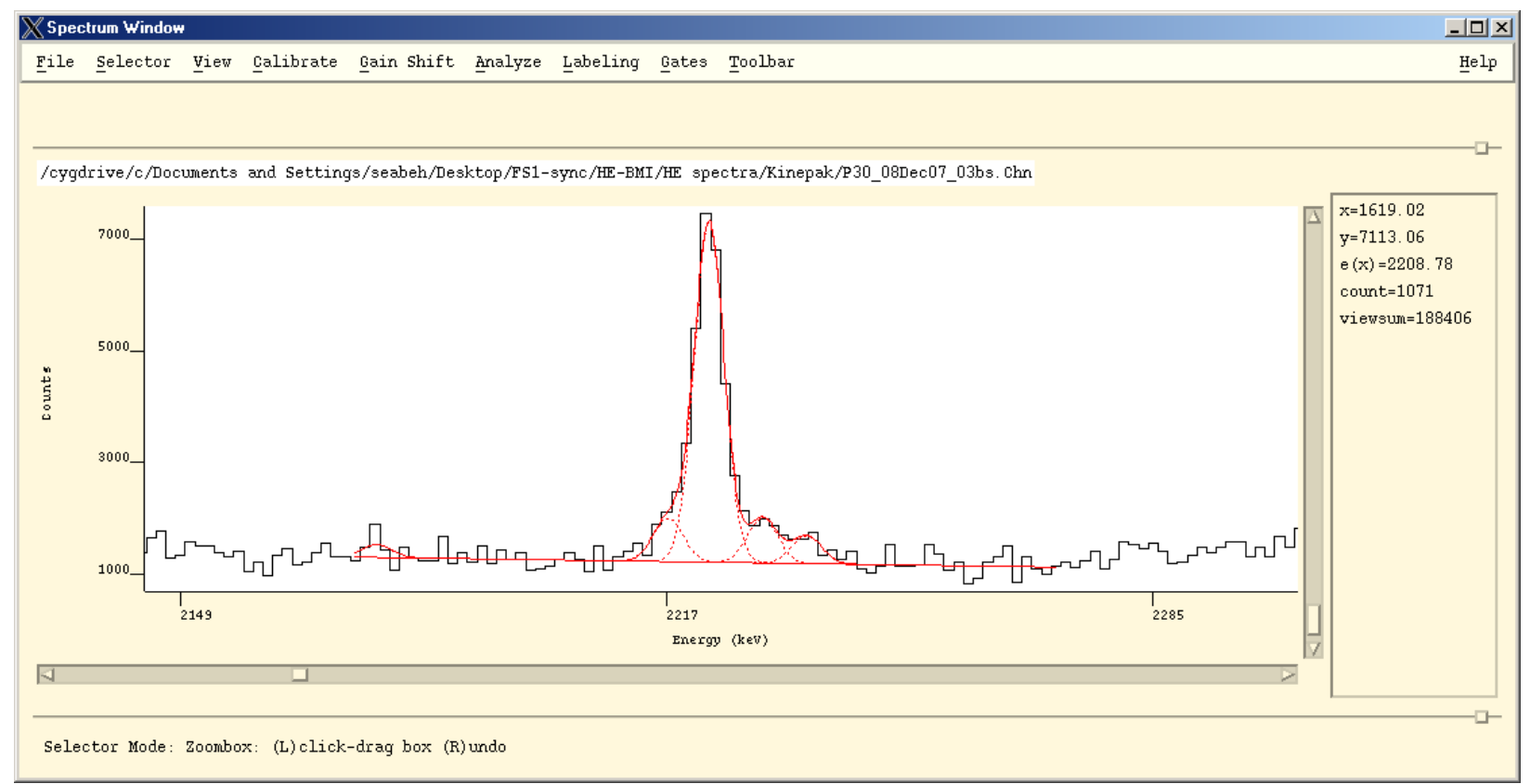

Figure 7. Gaussian fit of hydrogen peak.

The elemental ratios described here are ratios of gamma-ray peak areas, not ratios of elemental concentrations or masses within the test items. These ratios are useful in particular for characterizing the responses of materials to the high-energy neutrons produced by a DT generator. The strongest gamma rays that correspond to interactions with hydrogen and nitrogen are due to thermal capture on those elements. The energy distribution of neutrons within an item however is strongly dependent both on the absolute quantity of test material present, as well as its geometry. A sheet of material produces a significantly different neutron-induced gamma response than a sphere of the same material with the same mass. In order to reduce effects of geometry and size, ratios of gamma rays produced by neutron interactions of approximately the same neutron energy are taken. In our measurements we are mostly concerned with the ratios of hydrogen to nitrogen (thermal capture) and carbon to oxygen (inelastic scattering). The neutron-energy thresholds for inelastic scattering off carbon and oxygen are close enough in energy that geometry and mass effects are removed [3].

The peak areas for the $2223 \mathrm{keV}$ hydrogen peak, the $10829 \mathrm{keV}$ nitrogen peak, and its first escape peak at $10318 \mathrm{keV}$ were obtained from the spectra for all of the explosives and simulants. These peak areas with their associated uncertainties can be found in Appendix A. The hydrogen to nitrogen ratio reported in the next section is the ratio of the hydrogen peak area to the sum of the nitrogen and nitrogen-escape peak areas. The carbon to oxygen ratio reported in the next section is the ratio of the $4439 \mathrm{keV}$ carbon peak to the sum of the $6129 \mathrm{keV}$ oxygen peak and its first excape peak at $5618 \mathrm{keV}$. The oxygen second escape peak at $5107 \mathrm{keV}$ was not used as it is contaminated by a nitrogen inelastic scattering peak at $5104 \mathrm{keV}$. In addition to the above peaks, the $2230 \mathrm{keV}$ peak from inelastic scattering off ${ }^{32} \mathrm{~S}$ was also determined for the cases of the black powder and its simulant. 


\section{RESULTS}

The peak area ratios were divided into two types: those from inalstic scattering and those from thermal neutron capture. The sections below describe the results for each type of ratio.

\subsection{Inelastic scattering peak area ratios}

The table below shows the carbon to oxygen ratios for the explosives and the simulants. As can be seen in the table, there is good agreement between the simulant and explosives for Detasheet, Semtex 1-A, and TNT. The C-4 and Red Dot ratios for the explosives and simulants are within two standard deviations of each other.

The explosive Detagel, was used as a substitute for Blastrite- 3 . The $\mathrm{C} / \mathrm{O}$ ratio for the Detagel and the simulated Blastrite- 3 are also within two standard deviations of each other. The black powder explosive and simulant have a large disagreement however. Part of this disagreement could be due to the packaging of the simulated black powder. This simulant was in three plastic bottles, although each bottle was less than half full. The plastic could be impacting the overall carbon to oxygen ratio. The explosive black powder was also in plastic bottles, but these bottles were approximately two-thirds full. The Z-Powder explosive and simulant also have strongly disagreeing carbon to oxygen ratios,.

\begin{tabular}{|l|l|l|}
\hline Explosive & HE C/O Ratio & Simulant C/O Ratio \\
\hline Black Powder & $1.07(0.12)$ & $2.49(0.06)$ \\
\hline Blastrite-3 & & $1.06(0.27)$ \\
\hline C-4 & $1.36(0.15)$ & $1.87(0.28)$ \\
\hline Detagel & $0.43(.07)$ & \\
\hline Detasheet & $1.32(0.17)$ & $1.27(0.14)$ \\
\hline Red Dot & $1.32(0.09)$ & $2.03(0.38)$ \\
\hline Semtex 1-A & $1.62(0.01)$ & $1.41(0.28)$ \\
\hline TNT & $1.98(0.16)$ & $1.97(0.51)$ \\
\hline Z-Powder & $0.58(0.05)$ & $1.07(0.01)$ \\
\hline
\end{tabular}

Table 1. C/O ratios for explosives and simulants. 
Table 2 shows the carbon to sulfur, sulfur to oxygen, and carbon to potassium ratios for the black powder explosive and simulant. As can be seen in the table, the carbon to sulfur ratio for the simulant is approximately a factor of two higher than that of the explosive. The sulfur to oxygen ratios however are in good agreement, and the carbon to potassium ratios are in relatively good agreement.. The discrepancy between the carbon to sulfur and carbon to oxygen ratios between the black powder simulant and explosive indicates that the carbon content of the simulant in its measurement configuration is likely higher than that of the real explosive. This is also indicated by the carbon to potassium ratio.

\begin{tabular}{|l|l|l|l|l|l|l|}
\hline Explosive & $\begin{array}{l}\text { HE C/S } \\
\text { Ratio }\end{array}$ & $\begin{array}{l}\text { Simulant } \\
\text { C/S Ratio }\end{array}$ & $\begin{array}{l}\text { HE S/O } \\
\text { Ratio }\end{array}$ & $\begin{array}{l}\text { Simulant } \\
\text { S/O Ratio }\end{array}$ & $\begin{array}{l}\text { Explosive } \\
\text { C/K Ratio }\end{array}$ & $\begin{array}{l}\text { Simulant } \\
\text { C/K Ratio }\end{array}$ \\
\hline $\begin{array}{l}\text { Black } \\
\text { Powder }\end{array}$ & $\begin{array}{l}2.11 \\
(0.56)\end{array}$ & $4.77(0.97)$ & $\begin{array}{l}0.53 \\
(0.11)\end{array}$ & $0.51(0.07)$ & $3.46(.26)$ & $4.29(.37)$ \\
\hline
\end{tabular}

Table 2. $\mathrm{C} / \mathrm{S}, \mathrm{S} / \mathrm{O}$, and $\mathrm{C} / \mathrm{K}$ ratios for explosives and simulants.

\subsection{Thermal neutron capture elemental ratios}

As described in previous sections, the primarly elemental ratio for thermal neutron capture is that of hydrogen to nitrogen. These spectra for these ratios were measured with the $252 \mathrm{Cf}-$ based system for the simulants in order to obtain better counting statistics on the nitrogen peaks. The ratios for the explosives were determined from the same spectra from which inelastic scattering ratios were obtained.

Table 3 shows the hydrogen to nitrogen ratios for both the explosives and their simulants. Some of the explosives measurements resulted in negative peak areas for nitrogen after background subtraction. These values were ignored as being non-physical in determining the average value of the hydrogen to nitrogen ratio, but were included in determining the standard deviation of the average. As can be seen in the table, while there is general agreement between the explosives and their simulants in the hydrogen to nitrogen ratio, the large variance in the ratios among sets of replicate measurements do not allow us to determine whether the simulants accurately represent the true elemental ratios present in the explosives. Even the ${ }^{252} \mathrm{Cf}$-based measurements on the simulants showed a high degree of variance among sets of replicate measurements. Nitrogen was detected in all of the ${ }^{252} \mathrm{Cf}$-based measurements however.

\begin{tabular}{|l|l|l|}
\hline Explosive & HE H/N Ratio & Simulant \\
\hline Black Cf H/N Ratio \\
\hline Blastrite-3 & $404(4000)$ & $967(490)$ \\
\hline
\end{tabular}




\begin{tabular}{|l|l|l|}
\hline C-4 & $125(492)$ & $552(212)$ \\
\hline Detagel & $258(11)$ & \\
\hline Detasheet & $248(1567)$ & $815(111)$ \\
\hline Red Dot & $331(201)$ & $1977(972)$ \\
\hline Semtex 1-A & $133(316)$ & $676(86)$ \\
\hline TNT & $624(225)$ & $742(419)$ \\
\hline Z-Powder & $100(25)$ & $1526(594)$ \\
\hline
\end{tabular}

Table 3. H/N ratios for explosives and simulants.

\subsection{Spectral overlays}

In addition to measuring peak areas and elemental ratios, another method for comparing the simulants with the explosives is to simply overlay spectra and visually examine the differences and similarities between the two. Examples of this can be seen in figures 8, 9 and 10 . Figure 8 shows an overlay of the hydrogen region of the spectra for the Red Dot explosive and simulant,figure 9 shows the oxygen region and figure 10 the nitrogen region.

The hydrogen peaks for the explosive and simulant spectra are evident in figure 8 . Direct comparisons of peak height inidicate the relative amounts of simulant and explosive more than the fraction of hydrogen in either the simulant or the explosive. The two peaks to the left of the hydrogen peak in the explosive spectrum are present in the background and in all the explosive spectra. Overlays of all the explosive and simulant spectra can be found in Appendix B. The simulants showed all the peaks of key elements that were present in the explosives spectra with the only exception being the Z-powder simulant. The Z-powder explosive showed strong chlorine peaks that were not evident in the simulant. These peaks were also not evident in the background spectra and can be attributed entirely to the explosive itself. 


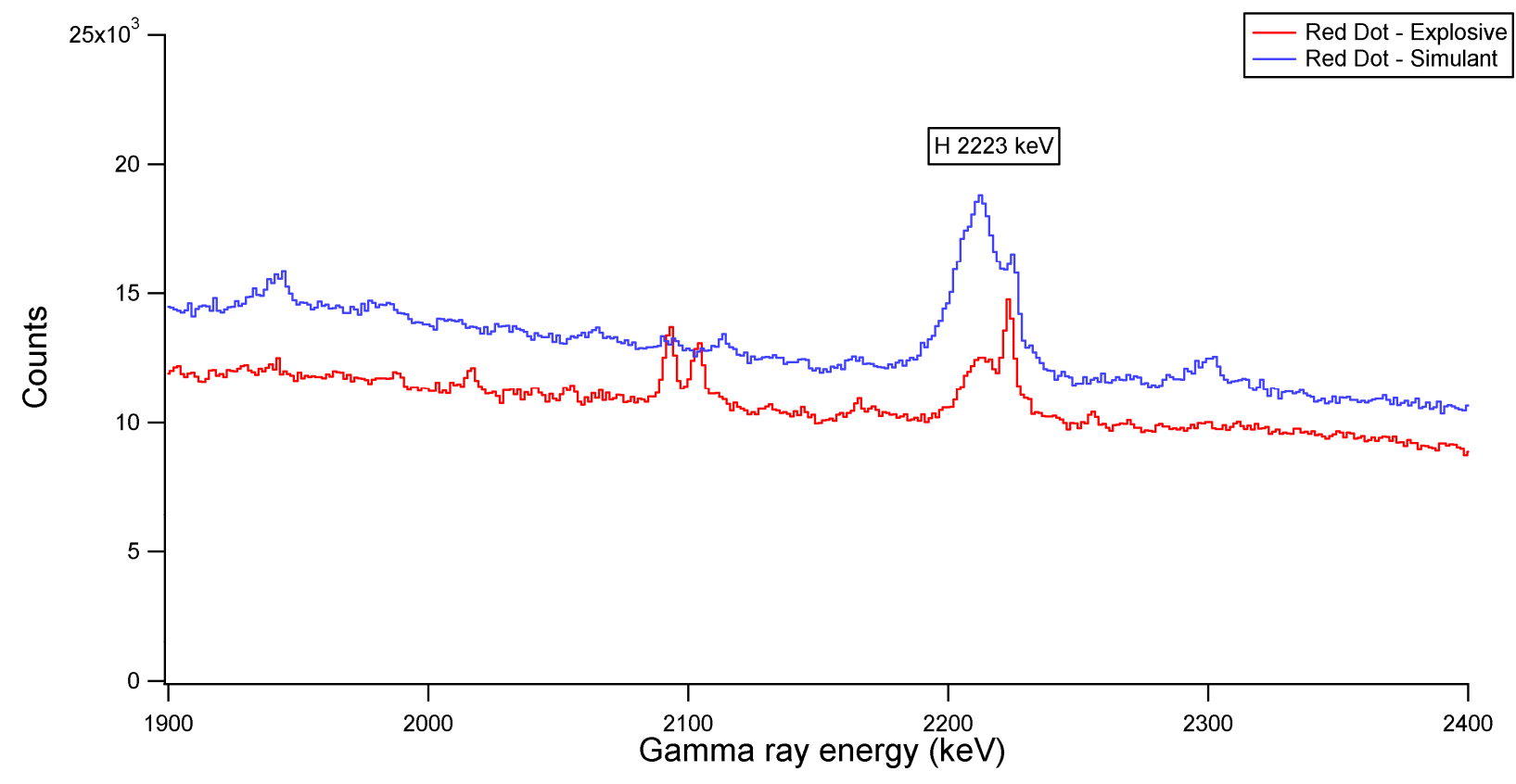

Figure 8. Hydrogen region in Red Dot explosive and simulant spectra. 


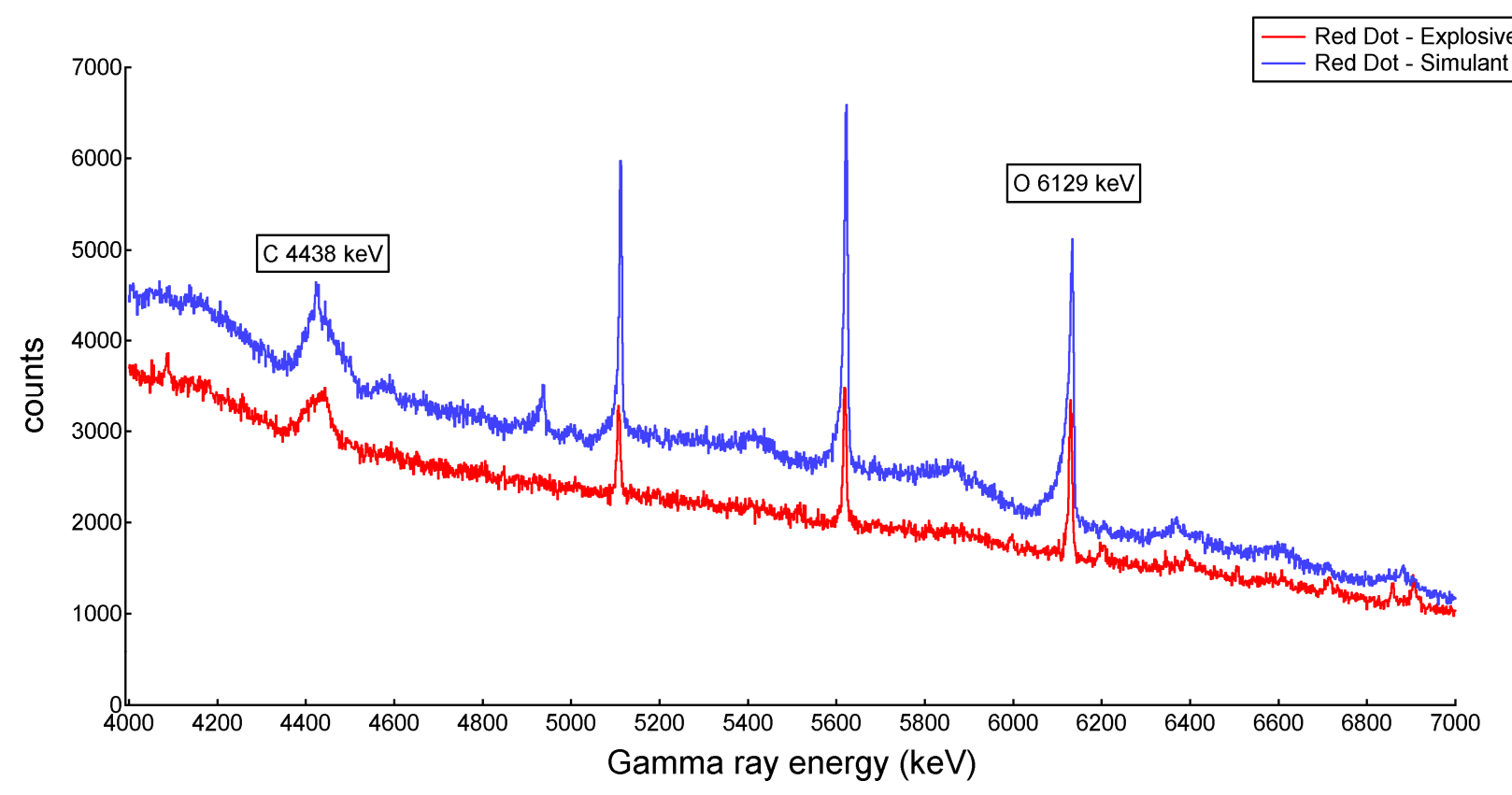

Figure 9. Oxygen region in Red Dot explosive and simulant spectra.

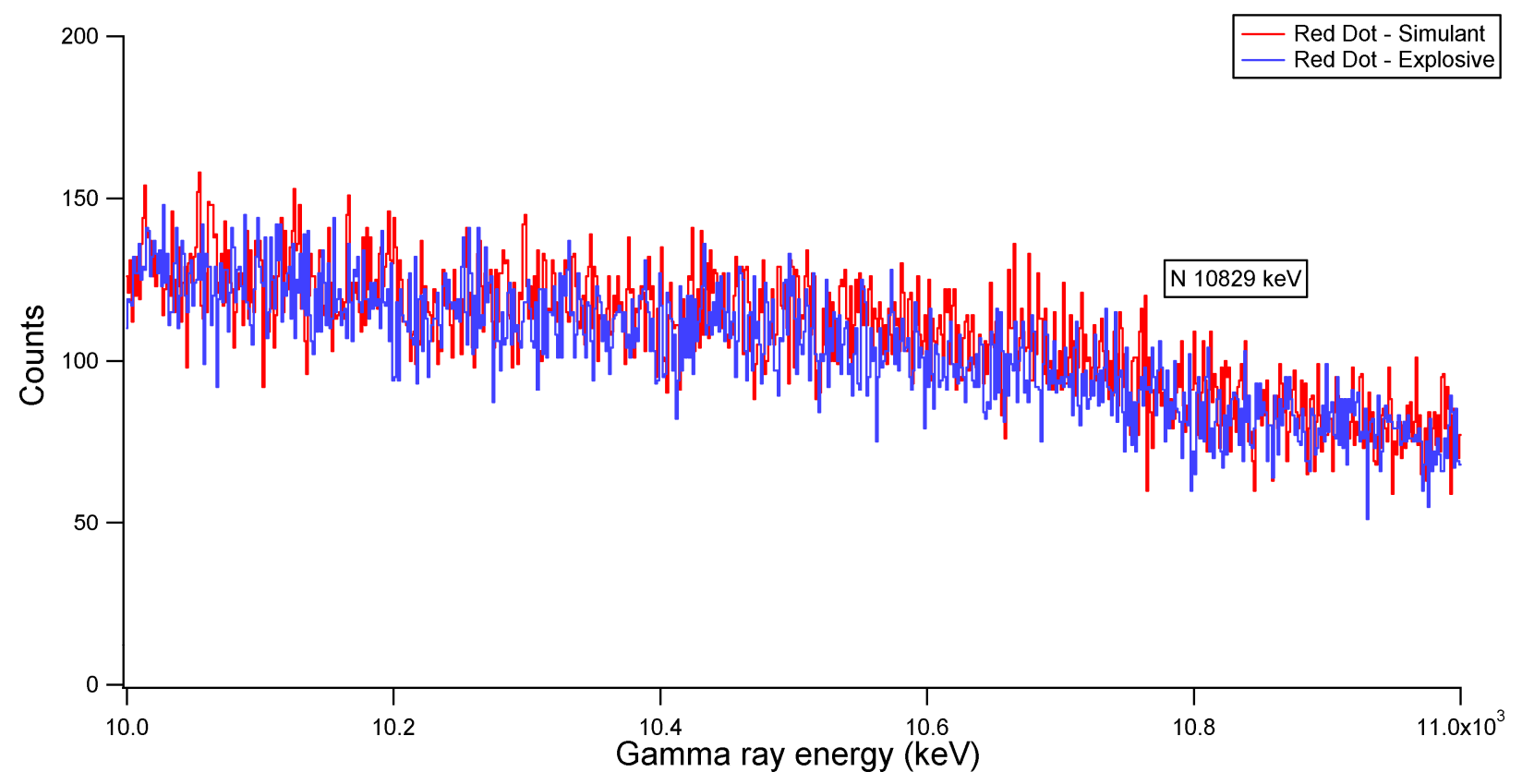

Figure 10. Nitrogen region in Red Dot explosive and simulant spectra. 


\section{CONCLUSIONS}

As can be seen in the previous section, in general there is relative agreement between the explosive and simulant carbon to oxygen ratios. One major exception to this is for the black powder simulant, which had a significantly higher carbon to oxygen ratio. The carbon to sulfur and carbon to potassium ratios showed similar disagreement between the simulant and explosive, indicating that there might be significantly higher carbon in the black powder simulant as it was configured for measurement. This was also indicated by the agreement between the sulfur to oxygen ratios between the simulant and the explosive. The Z-powder simulant also had significant disagreement with the explosive in its carbon to oxygen ratio, in addition to showing no sign of the strong chlorine peaks present in the explosive.

The hydrogen to nitrogen ratios, although in general agreement between the simulants and the explosives, show a high degree of variance among replicate measurements. This is due to the poor statistics on the nitrogen thermal capture peaks. 


\section{REFERENCES}

1. A.J. Caffrey, J.D. Cole, R.J. Gehrke, and R.C. Greenwood, "Chemical warfare agent and high explosive identification by spectroscopy of neutron-induced gamma rays", IEEE Transactions on Nuclear Science, 39 (1992) pp 1422-1426

2. A.E. Egger, M.H. Putnam, R.G. Helmer, A.J. Caffrey, and R.C. Greenwood, "Gauss IX: An Interactive Program for the Analysis of Gamma-Ray Spectra from Ge Semiconductor Detectors," IEEE Transactions on Nuclear Science 42 (1994) pp. 267-271.

3. E.H. Seabury and A.J. Caffrey, "Explosive Detection by PGNAA", Idaho National Engineering and Environmental Laboratory Report INEEL-EXT-04-02475, 2004. 
Appendix A

Peak Areas for Explosives and Simulants 


\section{Appendix A \\ Peak Areas for Explosives and Simulants}

Simulant Measurements ${ }^{252} \mathrm{Cf}$ source

\begin{tabular}{|c|c|c|c|c|c|c|c|c|c|c|}
\hline Simulant & File-ID & Live Time & H-2223 & unc & $\mathrm{N}-\mathrm{Sum}$ & Unc & Nsum-Ne & Nsum-N & $\begin{array}{l}\text { Nsum- } \\
\text { sum }\end{array}$ & unc \\
\hline Black Powder & P15_13Jul07_42 & 6000 & 26136 & 250 & 51.7 & 9.466784 & 36.575 & 6.7 & 43.275 & 7.924083 \\
\hline Black Powder & P15_12Jul07_36 & 6000 & 28204 & 265 & 34.8 & 8.823831 & 22.5625 & 15.35 & 37.9125 & 9.613032 \\
\hline Black Powder & P15_02Aug07_06 & 6000 & 22329 & 241 & 28.9 & 7.924645 & 3.825 & 16.5125 & 20.3375 & 5.576729 \\
\hline Black Powder & P15_06Aug07_15 & 6000 & 27315 & 257 & 15.8 & 7.262231 & 11.3875 & 4.05 & 15.4375 & 7.095613 \\
\hline Black Powder & P15_24Aug07_06 & 6000 & 14970 & 222 & 23.2 & 7.566373 & 20.925 & 3.2 & 24.125 & 7.868049 \\
\hline blastrite & P15_06Sep07_06 & 3000 & 119584 & 541 & 77.8 & 11.89664 & 63.8125 & 12.812 & 76.6245 & 11.71689 \\
\hline blastrite & P15_06Sep07_12 & 3000 & 102675 & 501 & 98.3 & 12.52996 & 90.7875 & 13.4875 & 104.275 & 13.29158 \\
\hline blastrite & P15_06Sep07_18 & 3000 & 105002 & 523 & 82 & 11.8072 & 61.7625 & 17.05 & 78.8125 & 11.34823 \\
\hline blastrite & P15_07Sep07_06 & 3000 & 130272 & 533 & 132 & 14.35584 & 104.5 & 24.525 & 129.025 & 14.03228 \\
\hline blastrite & P15_07Sep07_12 & 3000 & 90645 & 489 & 71.7 & 10.8706 & 60.35 & 13.9625 & 74.3125 & 11.26669 \\
\hline C-4 & P15_12Jul07_06 & 3000 & 44213 & 331 & 131.5 & 12.75813 & 93.825 & 37.987 & 131.812 & 12.7884 \\
\hline C-4 & P15_12Jul07_42 & 3000 & 34305 & 299 & 91.6 & 11.07881 & 69.275 & 30 & 99.275 & 12.00708 \\
\hline C-4 & P15_02Aug07_15 & 3000 & 17924 & 206 & 32.9 & 9.124144 & 18.675 & 4.0875 & 22.7625 & 6.312715 \\
\hline C-4 & P15_06Aug07_09 & 3000 & 25976 & 232 & 44.5 & 8.504117 & 10.8625 & 24.225 & 35.0875 & 6.705353 \\
\hline C-4 & P15_23Aug07_03 & 3000 & 21939 & 226 & 42.1 & 8.184131 & 33.2125 & 6.6875 & 39.9 & 7.756457 \\
\hline Detasheet & P15_13Jul07_24 & 3000 & 44859 & 344 & 60.2 & 9.381365 & 43.45 & 20.112 & 63.562 & 9.905287 \\
\hline Detasheet & P15_12Jul07_18 & 3000 & 43932 & 323 & 54.7 & 9.042677 & 48.6875 & 12.6625 & 61.35 & 10.14201 \\
\hline Detasheet & P15_16Jul07_03 & 3000 & 58225 & 363 & 65.5 & 9.947864 & 56.1625 & 15.3 & 71.4625 & 10.85342 \\
\hline Detasheet & P15_16Jul07_06 & 3000 & 40260 & 312 & 43 & 8.19878 & 38.1625 & 10.4375 & 48.6 & 9.266529 \\
\hline Detasheet & P15_17Jul07_06 & 3000 & 40550 & 318 & 41 & 8.112336 & 38.35 & 11.89 & 50.24 & 9.94058 \\
\hline Detasheet & P15_17Jul07_12 & 3000 & 40979 & 316 & 41.6 & 8.19878 & 33.575 & 6.775 & 40.35 & 7.952423 \\
\hline RedDot & P15_13Jul07_12 & 6000 & 62169 & 461 & 70.7 & 10.84666 & 48.925 & 21.112 & 70.037 & 10.74494 \\
\hline RedDot & P15_02Aug07_12 & 6000 & 61839 & 3716 & 56.9475 & 10.30049 & 10.3625 & 8.6625 & 19.025 & 3.441182 \\
\hline RedDot & P15_06Aug07_21 & 6000 & 65653 & 3837 & 47.384 & 9.381365 & 22.8875 & 10.7125 & 33.6 & 6.652327 \\
\hline RedDot & P15_24Aug07_12 & 6000 & 65608 & 3387 & 38.7 & 8.91852 & 29.8625 & 6.2626 & 36.1251 & 8.325127 \\
\hline Semtex & P15_13Jul07_18 & 3000 & 44181 & 345 & 66.6 & 9.679876 & 48.775 & 24.225 & 73 & 10.61007 \\
\hline Semtex & P15_12Jul07_24 & 3000 & 45931 & 322 & 75.3 & 10.13558 & 50.2999 & 21.4625 & 71.7624 & 9.65941 \\
\hline
\end{tabular}




\begin{tabular}{|c|c|c|c|c|c|c|c|c|c|c|}
\hline Semtex & P15_16Jul07_10 & 4000 & 66639 & 389 & 109.7 & 12.14331 & 85.9 & 23.49 & 109.39 & 12.109 \\
\hline Semtex & P15_16Jul07_12 & 2000 & 29450 & 260 & 39.1 & 7.566373 & 32.737 & 8.025 & 40.762 & 7.887992 \\
\hline Semtex & P15_16Jul07_15 & 3000 & 45041 & 331 & 58.9 & 9.360021 & 35.85 & 20.112 & 55.962 & 8.893133 \\
\hline TNT & P15_13Jul07_30 & 3000 & 27562 & 290 & 67.3 & 9.689685 & 55.7875 & 17.8625 & 73.65 & 10.60394 \\
\hline TNT & P15_12Jul07_12 & 3000 & 32679 & 293 & 79 & 10.27278 & 65.45 & 19.2 & 84.65 & 11.00748 \\
\hline TNT & P15_06Aug07_06 & 6000 & 66024 & 4163 & 60.4 & 10.31746 & 46.075 & 11.55 & 57.625 & 9.843439 \\
\hline TNT & P15_24Aug07_15 & 3000 & 29344 & 2912 & 29.9 & 7.211103 & 30.2625 & -2.65 & 27.6125 & 6.659417 \\
\hline Z-Powder & P15_06Sep07_03 & 3000 & 29678 & 2747 & 16 & 6.324555 & 8.125 & 6.4625 & 14.5875 & 5.766216 \\
\hline Z-Powder & P15_06Sep07_09 & 3000 & 28453 & 3257 & 18.3 & 6.441273 & 11.2375 & 1.5875 & 12.825 & 4.514171 \\
\hline Z-Powder & P15_06Sep07_15 & 3000 & 28453 & 3257 & 31.2 & 7.206941 & 30.475 & 3.35 & 33.825 & 7.813294 \\
\hline Z-Powder & P15_07Sep07_03 & 3000 & 32151 & 4013 & 24.1 & 6.935416 & 24.25 & 5.575 & 29.825 & 8.582937 \\
\hline Z-Powder & P15_07Sep07_09 & 3000 & 35016 & 3379 & 25.4 & 7.119691 & 19.125 & 4.8875 & 24.0125 & 6.730771 \\
\hline
\end{tabular}

Simulant Measurements DT source

\begin{tabular}{|c|c|c|c|c|c|c|c|c|c|}
\hline Simulant & File-ID & Live Time & $\mathrm{Bi}-1608$ & unc & S-2230 & unc & $\begin{array}{l}\text { K- } \\
2813\end{array}$ & Unc & C-4439 \\
\hline Blastrite-3 & P15_04Sep07_07 & 6000 & 125210 & 2000 & & & & & 17636 \\
\hline Blastrite-3 & P15_04Sep07_13 & 6000 & 111222 & 2000 & & & & & 17702 \\
\hline Blastrite-3 & P15_05Sep07_07 & 6000 & 109614 & 2000 & & & & & 17815 \\
\hline Blastrite-3 & P15_05Sep07_19 & 6000 & 134933 & 2000 & & & & & 16125 \\
\hline Black Powder & P15_08Aug07_07 & 6000 & 144797 & 849 & 6872 & 119 & 8390 & 701 & 36859 \\
\hline Black Powder & P15_08Aug07_22 & 3000 & 681170 & 587 & 4904 & 93 & 4230 & 619 & 15830 \\
\hline Black Powder & P15_09Aug07_13 & 6000 & 134137 & 850 & 7126 & 111 & 6550 & 598 & 31279 \\
\hline Black Powder & P15_13Aug07_07 & 6000 & 130063 & 811 & 5988 & 89 & 7764 & 640 & 33574 \\
\hline Black Powder & P15_15Aug07_19 & 6000 & 126446 & 890 & 6620 & 98 & 8280 & 918 & 34722 \\
\hline C-4 & P15_07Aug07_17 & 3997 & 92481 & 713 & & & & & 11409 \\
\hline C-4 & P15_08Aug07_13 & 5998 & 134464 & 861 & & & & & 16459 \\
\hline$C-4$ & P15_10Aug07_07 & 5997 & 135085 & 895 & & & & & 14282 \\
\hline C-4 & P15_14Aug07_07 & 6000 & & & & & & & \\
\hline C-4 & P15_15Aug07_13 & 5997 & 122223 & 874 & & & & & 18234 \\
\hline C-4 & P15_16Aug07_07 & 5998 & 110248 & 789 & & & & & 18335 \\
\hline Red Dot & P15_07Aug07_07 & 6000 & 146422 & 883 & & & & & 40114 \\
\hline Red Dot & P15_09Aug07_07 & 6000 & 137159 & 827 & & & & & 44158 \\
\hline Red Dot & P15_10Aug07_19 & 6000 & 128588 & 855 & & & & & 30141 \\
\hline Red Dot & P15_13Aug07_13 & 6000 & 119903 & 801 & & & & & 43596 \\
\hline
\end{tabular}

$\begin{array}{rlrrrr} & \text { uncr } & \text { O-5618 } & \text { unc } & \text { O-6129 } & \text { unc } \\ 260 & 1410.88 & 8223 & 141 & 8890 & 157 \\ 2000 & 1416.16 & 8626 & 113 & 6246 & 99 \\ 245 & 1425.2 & 13986 & 216 & 11118 & 184 \\ 212 & 1290 & 6906 & 115 & 5364 & 118 \\ 272 & 2948.72 & 6129 & 96 & 6913 & 113 \\ 179 & 1266.4 & 5523 & 80 & 4099 & 68 \\ 265 & 2502.32 & 10616 & 117 & 7160 & 97 \\ 251 & 2685.92 & 5900 & 88 & 4368 & 86 \\ 3000 & 2777.76 & 7402 & 96 & 4461 & 80 \\ 200 & 912.72 & 9208 & 109 & 7648 & 102 \\ 184 & 1316.72 & 5922 & 90 & 5198 & 81 \\ 203 & 1142.56 & 3750 & 75 & 2945 & 67 \\ & & & & & \\ 214 & 1458.72 & 5426 & 89 & 3810 & 74 \\ 209 & 1466.8 & 4407 & 101 & 5384 & 119 \\ 332 & 3209.12 & 10575 & 158 & 9846 & 154 \\ 297 & 3532.64 & 11642 & 148 & 14973 & 185 \\ 159 & 2411.28 & 9212 & 97 & 6390 & 83 \\ 267 & 3487.68 & 7669 & 102 & 9370 & 123\end{array}$




$\begin{array}{llllll}\text { TNT } & \text { P15_07Aug07_13 } & 6000 & 135368 & 798 & 34089 \\ \text { TNT } & \text { P15_08Aug07_19 } & 6000 & 135127 & 814 & 33438 \\ \text { TNT } & \text { P15_09Aug07_19 } & 6000 & 136802 & 850 & 33717 \\ \text { TNT } & \text { P15_10Aug07_13 } & 6000 & 120694 & 806 & 37096 \\ \text { TNT } & \text { P15_13Aug07_19 } & 6000 & 118782 & 796 & 31015 \\ \text { TNT } & \text { P15_15Aug07_07 } & 6000 & 125042 & 840 & 30786 \\ \text { TNT } & \text { P15_16Aug07_13 } & 6000 & 118546 & 850 & 25744 \\ \text { Z-powder } & \text { P15_29Aug07_07 } & 6000 & 121558 & 879 & 28027 \\ \text { Z-powder } & \text { P15_30Aug07_07 } & 6000 & 118735 & 873 & 26244 \\ \text { Z-powder } & \text { P15_30Aug07_13 } & 6000 & 124235 & 885 & 29876 \\ \text { Z-powder } & \text { P15_05Sep07_13 } & 6000 & 119256 & 809 & 34861 \\ \text { Detasheet } & \text { P15_19Jul07_08 } & 6000 & 127208 & 718 & 31708 \\ \text { Detasheet } & \text { P15_19Jul07_20 } & 6000 & 122116 & 704 & 27195 \\ \text { Detasheet } & \text { P15_24Jul07_08 } & 6000 & 122969 & 741 & 29074 \\ \text { Detasheet } & \text { P15_26Jul07_13 } & 6000 & 112659 & 736 & 31761 \\ \text { Semtex 1-A } & \text { P15_17Jul07_20 } & 6000 & 129841 & 696 & 31473 \\ \text { Semtex 1-A } & \text { P15_18Jul07_08 } & 6000 & 125055 & 684 & 30203 \\ \text { Semtex 1-A } & \text { P15_19Jul07_14 } & 6000 & 120760 & 685 & 26320 \\ \text { Semtex 1-A } & \text { P15_24Jul07_14 } & 6000 & 125925 & 763 & \end{array}$

$\begin{array}{rrrrrr}304 & 2727.12 & 13575 & 128 & 11007 & 119 \\ 248 & 2675.04 & 9824 & 112 & 7732 & 99 \\ 251 & 2697.36 & 11793 & 117 & 8944 & 104 \\ & & & & & \\ 246 & 2967.68 & 10993 & 117 & 8000 & 98 \\ 271 & 2481.2 & 7596 & 121 & 7225 & 131 \\ 237 & 2462.88 & 5899 & 93 & 4784 & 90 \\ 254 & 2059.52 & 10267 & 166 & 15637 & 200 \\ 298 & 2242.16 & 13303 & 195 & 14743 & 193 \\ 269 & 2099.52 & 9294 & 119 & 11995 & 181 \\ 286 & 2390.08 & 12756 & 159 & 16091 & 223 \\ 333 & 2788.88 & 12282 & 155 & 17556 & 190 \\ 336 & 2536.64 & 14294 & 140 & 13776 & 134 \\ 246 & 2175.6 & 8174 & 124 & 12121 & 157 \\ 251 & 2325.92 & 10995 & 122 & 9317 & 110 \\ 321 & 2540.88 & 14899 & 148 & 13751 & 135 \\ 336 & 2517.84 & 9314 & 126 & 8347 & 136 \\ 322 & 2416.24 & 12278 & 130 & 10179 & 116 \\ 236 & 2105.6 & 11195 & 123 & 7551 & 99\end{array}$

Explosive Measurements DT source

\begin{tabular}{|c|c|c|c|c|c|c|c|c|c|c|c|c|c|c|c|c|}
\hline Explosive & File-ID & Live Time & $\mathrm{Pb}-2614$ & unc & H-2223 & unc & S-2230 & unc & C-4439 & unc & $0-5618$ & unc & $0-6129$ & unc & N-10318 & 10829 \\
\hline Black Powder & P30_18Jan08_03 & 3000 & 79285 & 449 & 19068 & 1320 & 22151 & 1122 & 33479 & 2678.32 & 14396 & 183 & 17547 & 184 & -11.525 & -15.4375 \\
\hline Black Powder & P30_18Jan08_08 & 2000 & 48116 & 350 & 13832 & 1000 & 8519 & 1000 & 27727 & 2218.16 & 10883 & 156 & 11474 & 148 & -1.125 & 30.8875 \\
\hline Black Powder & P30_18Jan08_11 & 2000 & 51241 & 359 & 8912 & 987 & 12334 & 859 & 21294 & 1703.52 & 10920 & 149 & 11179 & 145 & 17.7875 & -1.3625 \\
\hline Black Powder & P30_19Jan08_03 & 3000 & 107655 & 574 & 12884 & 889 & 16780 & 785 & 33408 & 2672.64 & 12613 & 166 & 14841 & 161 & -47.65 & 36.2875 \\
\hline Black Powder & P30_19Jan08_06 & 3000 & 65569 & 448 & 14170 & 1801 & 14062 & 1303 & 29069 & 2325.52 & 11791 & 146 & 14303 & 150 & 27.5625 & -7.825 \\
\hline Black Powder & P30_19Jan08_10 & 4000 & 90887 & 495 & 17080 & 2401 & 16912 & 1946 & 32793 & 2623.44 & 16045 & 165 & 19187 & 182 & 47.025 & 44.0125 \\
\hline Black Powder & P30_19Jan08_14 & 4000 & 86536 & 494 & 17278 & 2757 & 16378 & 2046 & 37337 & 2986.96 & 16799 & 185 & 20187 & 182 & 23.725 & 31.1125 \\
\hline C-4 & P30_08Dec07_03 & 3000 & 76015 & 407 & 26524 & 205 & & & 23874 & 1909.92 & 7958 & 122 & 7907 & 119 & 171.25 & 56.737 \\
\hline C-4 & P30_08Dec07_06 & 3000 & 75586 & 458 & 37654 & 232 & & & 23282 & 1862.56 & 8836 & 124 & 9755 & 127 & 200.24 & 136.61 \\
\hline C-4 & P30_08Dec07_09 & 3000 & 72683 & 424 & 37203 & 227 & & & 25508 & 2040.64 & 8374 & 128 & 8189 & 124 & 167.68 & 115.13 \\
\hline$C-4$ & P30_08Dec07_12 & 2500 & 60859 & 426 & 50202 & 262 & & & 21826 & 1746.08 & 8086 & 137 & 9093 & 132 & 195.7 & 177.3 \\
\hline C-4 & P30_15Dec07_14 & 3000 & 81635 & 432 & 42844 & 251 & & & 24947 & 1995.76 & 10321 & 140 & 10176 & 129 & 23.3125 & 13.175 \\
\hline Detasheet & P30_25Jan08_03 & 3000 & 69967 & 444 & 24024 & 207 & & & 21457 & 1716.56 & 7513 & 120 & 8513 & 132 & 81.15 & 23.3875 \\
\hline
\end{tabular}




\begin{tabular}{|c|c|c|c|c|c|c|c|c|c|c|c|c|c|c|}
\hline Detasheet & P30_25Jan08_06 & 3000 & 70619 & 432 & 21543 & 205 & 21431 & 1714.48 & 9739 & 140 & 9314 & 138 & 38.09999 & 46.025 \\
\hline Detasheet & P30_25Jan08_09 & 2500 & 60524 & 417 & 17638 & 185 & 19712 & 1576.96 & 7542 & 136 & 7962 & 130 & -15.1 & -14.275 \\
\hline Detasheet & P30_26Jan08_03 & 3000 & 75195 & 462 & 27267 & 225 & 30872 & 2469.76 & 10318 & 166 & 9183 & 159 & 19.7875 & -37.9625 \\
\hline Detasheet & P30_26Jan08_06 & 3000 & 70802 & 453 & 27015 & 232 & 30677 & 2454.16 & $\begin{array}{l}11332 \\
32495\end{array}$ & $\begin{array}{l}169 \\
273\end{array}$ & $\begin{array}{l}12276 \\
27834\end{array}$ & $\begin{array}{l}189 \\
270\end{array}$ & $\begin{array}{r}-3.9375 \\
354.625\end{array}$ & $\begin{array}{r}-3.35 \\
145.525\end{array}$ \\
\hline Detagel & P10_11Apr08_12 & 3000 & 54471 & 459 & 129562 & 475 & 31127 & 522 & 30815 & 263 & 26395 & 273 & 286.95 & 212.087 \\
\hline Detagel & P10_11Apr08_09 & 3000 & 53504 & 407 & 126174 & 457 & 20514 & 474 & 30128 & 256 & 25860 & 261 & 288.25 & 169.58 \\
\hline Detagel & P10_11Apr08_06 & 3000 & 51886 & 555 & 125110 & 459 & 25223 & 501 & 33514 & 298 & 27655 & 295 & 341.625 & 177.575 \\
\hline Detagel & P10_11Apr08_03 & 3000 & 51286 & 595 & 128688 & 467 & 23857 & 475 & & & & & & \\
\hline Red Dot & P30_14Dec07_03 & 3000 & 79468 & 458 & 10746 & 148 & 26045 & 2083.6 & 8325 & 125 & 12073 & 141 & 18.6625 & 10.7625 \\
\hline Red Dot & P30_14Dec07_05 & 2000 & 50758 & 360 & 12409 & 160 & 19745 & 1579.6 & 7822 & 118 & 8605 & 121 & 24.7999 & 9 \\
\hline Red Dot & P30_14Dec07_08 & 3000 & 75148 & 408 & 12400 & 234 & 30031 & 2402.48 & 10685 & 141 & 11375 & 139 & 72.7625 & 6.95 \\
\hline Red Dot & P30_14Dec07_11 & 3000 & 75745 & 401 & 12672 & 167 & 31433 & 2514.64 & 11130 & 139 & 10763 & 138 & 2.325 & 16.525 \\
\hline Red Dot & P30_15Dec07_06 & 3000 & 92576 & 467 & 14464 & 216 & 31218 & 2497.44 & 12450 & 168 & 12359 & 167 & 5.1 & 67.5875 \\
\hline Red Dot & P30_15Dec07_11 & 5000 & 127756 & 543 & 36783 & 265 & 52699 & 4215.92 & 18932 & 206 & 19853 & 187 & 76.6999 & 90.849 \\
\hline Semtex 1-A & P30_22Feb08_06 & 6000 & 167151 & 690 & 14946 & 136 & 23756 & 1900.48 & 6561 & 107 & 7602 & 110 & -9.0625 & -43.375 \\
\hline Semtex 1-A & P30_22Feb08_12 & 6000 & 168509 & 687 & 14670 & 125 & 25865 & 2069.2 & 7224 & 96 & 7179 & 99 & 6.1375 & 37.9875 \\
\hline Semtex 1-A & P30_22Feb08_14 & 2000 & 55951 & 382 & 4291 & 70 & 7096 & 567.68 & 2415 & 49 & 2414 & 49 & 44.3625 & -4.575 \\
\hline Semtex 1-A & P30_23Feb08_06 & 6000 & 153117 & 624 & 11644 & 144 & 20013 & 1601.04 & 5379 & 145 & 6193 & 123 & -57.2 & 46.3125 \\
\hline Semtex 1-A & P30_23Feb08_09 & 3000 & 71917 & 433 & 6227 & 96 & 9554 & 764.32 & 2964 & 70 & 3812 & 75 & -3.4625 & -21.5375 \\
\hline TNT & P30_26Jan08_10 & 4000 & 98115 & 521 & 25267 & 250 & 54732 & 4378.56 & 13369 & 175 & 10568 & 162 & 75.0376 & -34.775 \\
\hline TNT & P30_09Feb08_04 & 4000 & 108753 & 570 & 31851 & 265 & 67698 & 5415.84 & 17258 & 203 & 16852 & 205 & 46.4 & -13.175 \\
\hline $\begin{array}{l}\text { TNT } \\
\text { Z-Powder }\end{array}$ & $\begin{array}{l}\text { P30_09Feb08_09 } \\
\text { P15_30May08_03 }\end{array}$ & $\begin{array}{l}4000 \\
3000\end{array}$ & $\begin{array}{l}115176 \\
51423\end{array}$ & $\begin{array}{l}583 \\
480\end{array}$ & $\begin{array}{c}28492 \\
39289\end{array}$ & $\begin{array}{l}209 \\
314\end{array}$ & $\begin{array}{c}73560 \\
39782\end{array}$ & $\begin{array}{l}5884.8 \\
495\end{array}$ & $\begin{array}{c}16072 \\
31854\end{array}$ & $\begin{array}{c}179 \\
239\end{array}$ & $\begin{array}{c}16792 \\
35063\end{array}$ & $\begin{array}{l}207 \\
256\end{array}$ & $\begin{array}{l}34.9875 \\
248.423\end{array}$ & $\begin{array}{r}35.7001 \\
162.4286\end{array}$ \\
\hline Z-Powder & P15_30May08_06 & 3000 & 45974 & 800 & 42521 & 355 & 31735 & 454 & 27461 & 232 & 30356 & 234 & 245.1968 & 166.9187 \\
\hline Z-Powder & P15_30May08_09 & 3000 & 46590 & 542 & 43720 & 381 & 35381 & 499 & 28389 & 229 & 31428 & 221 & 245.9872 & 170.7929 \\
\hline Z-Powder & P15_30May08_12 & 3000 & 45289 & 782 & 41801 & 352 & 38281 & 501 & 32053 & 237 & 35552 & 241 & 251.424 & 179.4 \\
\hline
\end{tabular}

Black Powder Explosive, Sulfur and Potassium Peaks DT source

Explosive File-ID Live Time $\mathrm{Pb}-2614$ unc $\mathrm{H}-2223$ unc $\mathrm{S}-2230$ K-2813 unc unc $\mathrm{C}-4439$ unc $0-5618$ unc $0-6129$ unc 


\begin{tabular}{|c|c|c|c|c|c|c|c|c|c|c|c|c|c|c|c|}
\hline Black Powder & P30_18Jan08_03 & 3000 & 79285 & 449 & 19068 & 1320 & 22151 & 9853 & 353 & 1122 & 33479 & 2678.32 & 14396 & 183 & 17547 \\
\hline Black Powder & P30_18Jan08_08 & 2000 & 48116 & 350 & 3832 & 1000 & 8519 & 224 & 321 & 1000 & 27727 & 2218.16 & 0883 & 156 & 1474 \\
\hline Black Powder & P30_18Jan08_11 & 2000 & 51241 & 359 & 8912 & 987 & 12334 & 6117 & 257 & 859 & 21294 & 703.52 & 0920 & 149 & 1179 \\
\hline Black Powder & P30_19Jan08_03 & 3000 & 107655 & 574 & 12884 & 889 & 16780 & 8488 & 304 & 785 & 33408 & 2672.64 & 12613 & 166 & 14841 \\
\hline Black Powder & P30_19Jan08_06 & 3000 & 65569 & 448 & 14170 & 1801 & 14062 & 9065 & 298 & 1303 & 29069 & 2325.52 & 11791 & 146 & 14303 \\
\hline Black Powder & P30_19Jan08_10 & 4000 & 90887 & 495 & 17080 & 2401 & 16912 & 11541 & 337 & 1946 & 32793 & 2623.44 & 16045 & 165 & 19187 \\
\hline Black Powder & P30_19Jan08_14 & 4000 & 86536 & 494 & 17278 & 2757 & 16378 & 11592 & 342 & 2046 & 37337 & 2986.96 & 16799 & 185 & 20187 \\
\hline
\end{tabular}


Appendix B

Spectral Overlays for Explosives and Simulants 


\section{Appendix B}

\section{Spectral Overlays for Explosives and Simulants}

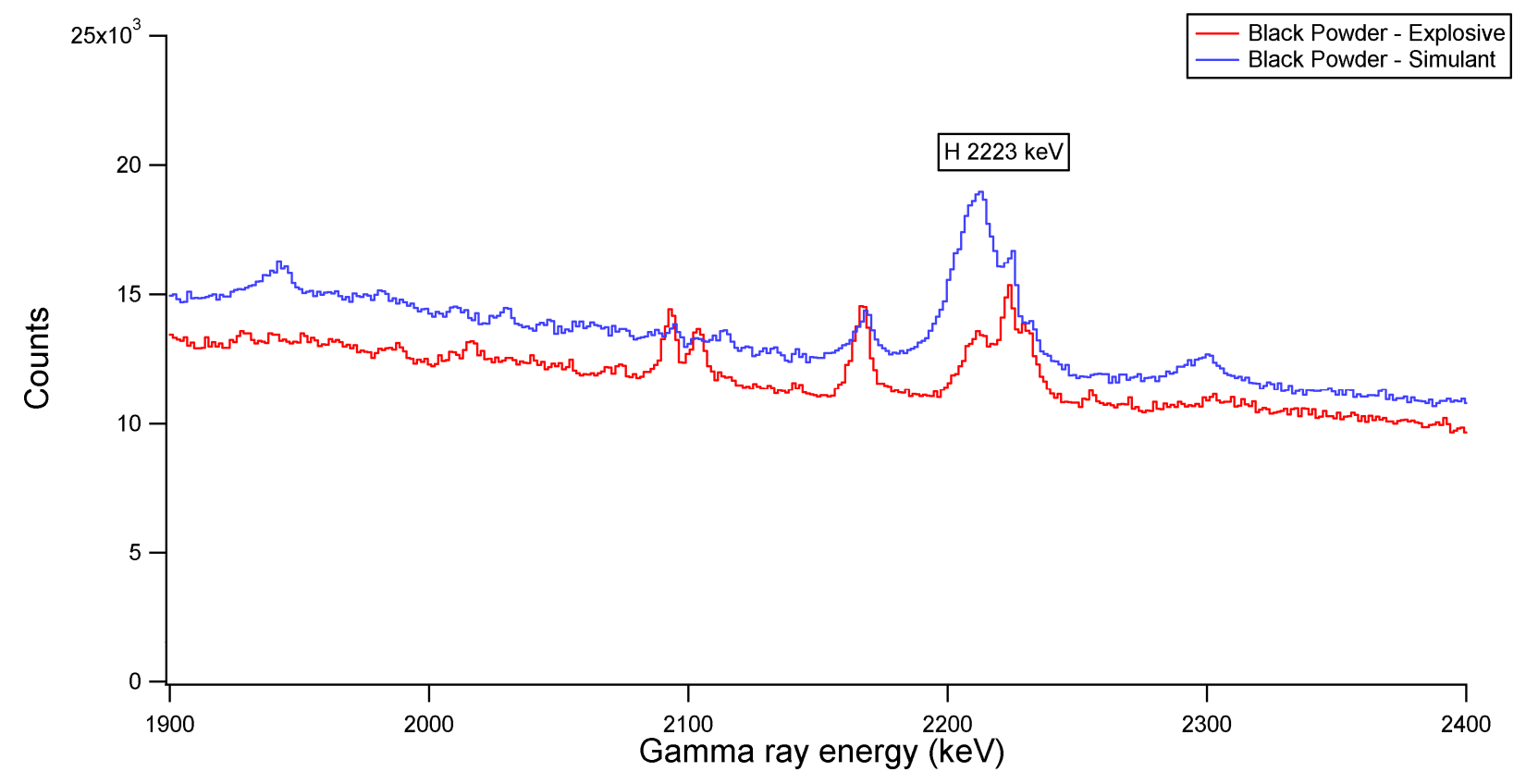

Figure B1. Hydrogen region of black powder explosive and simulant spectrat

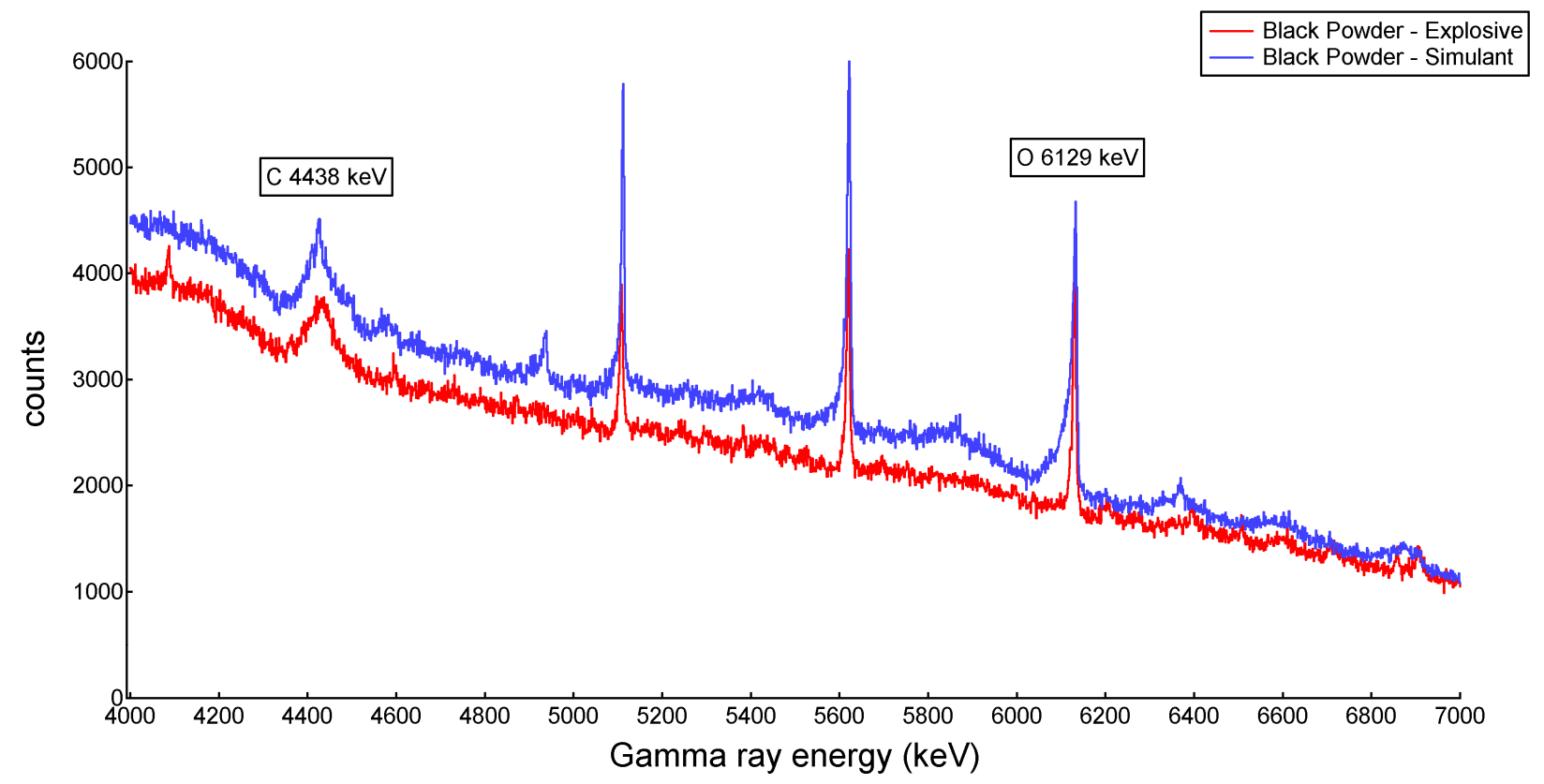


Figure B2. Oxygen region of black powder explosive and simulant spectra

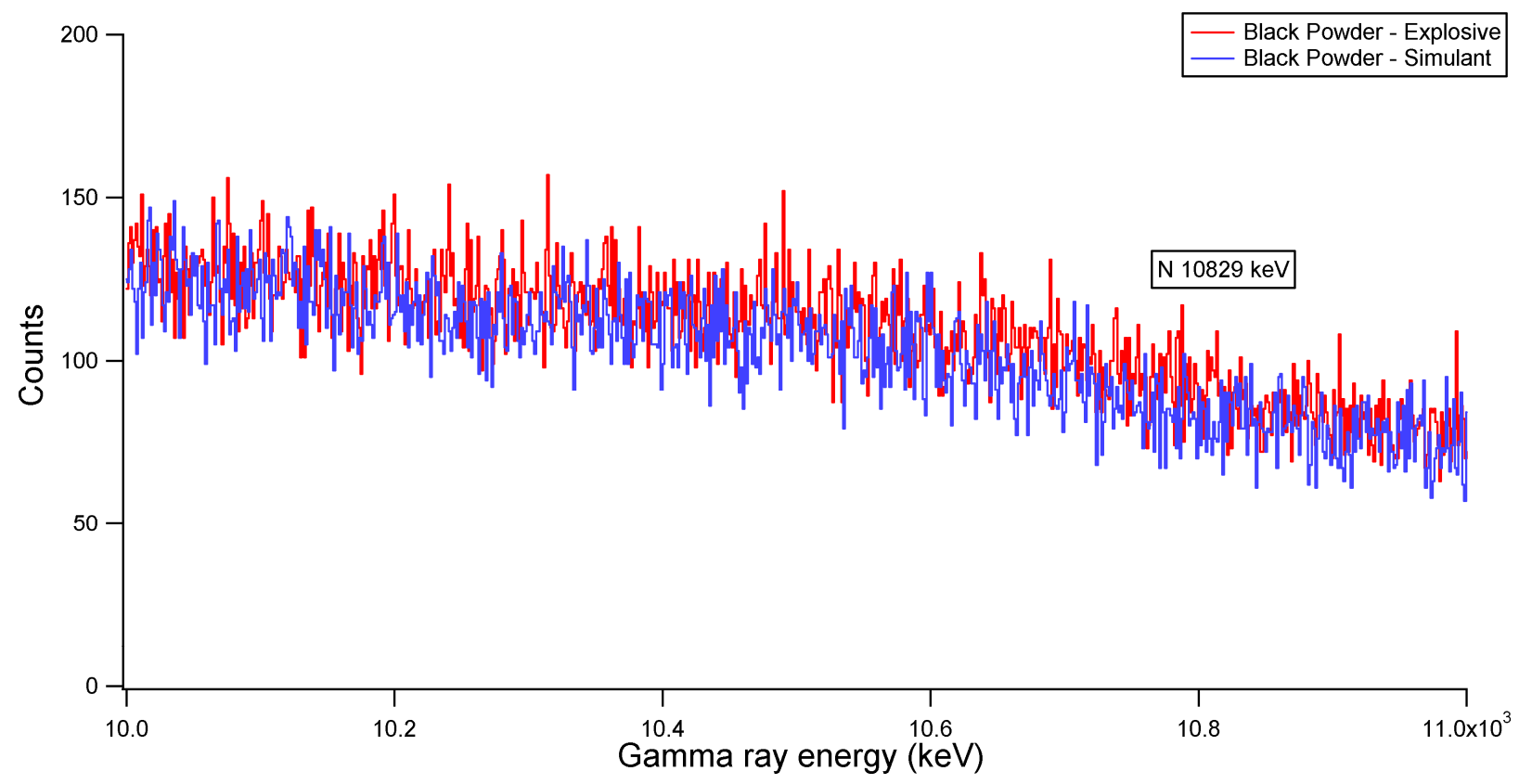

Figure B3. Nitrogen region of black powder explosive and simulant spectra.

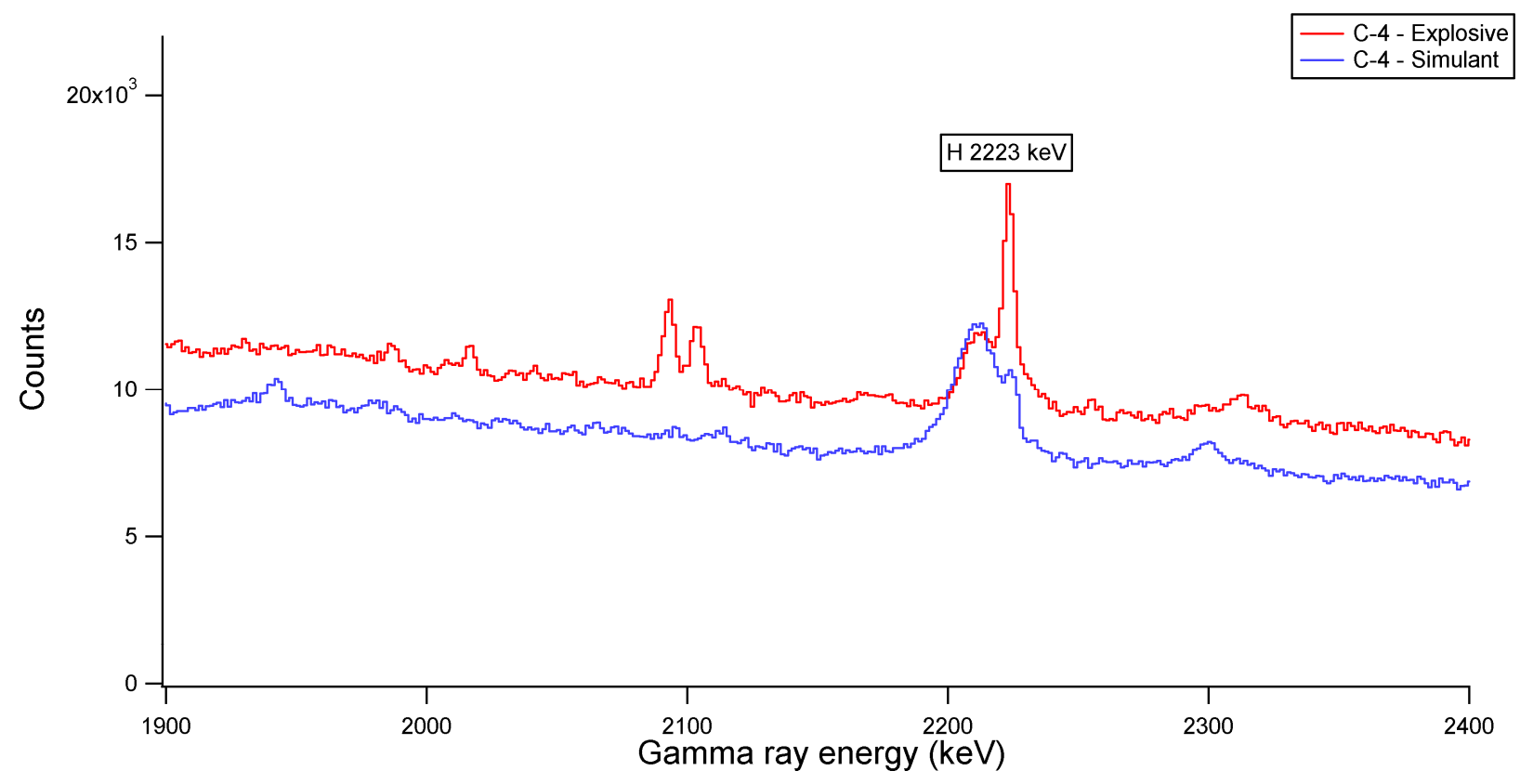


Figure B4. Hydrogen region of C-4 explosive and simulant spectra.

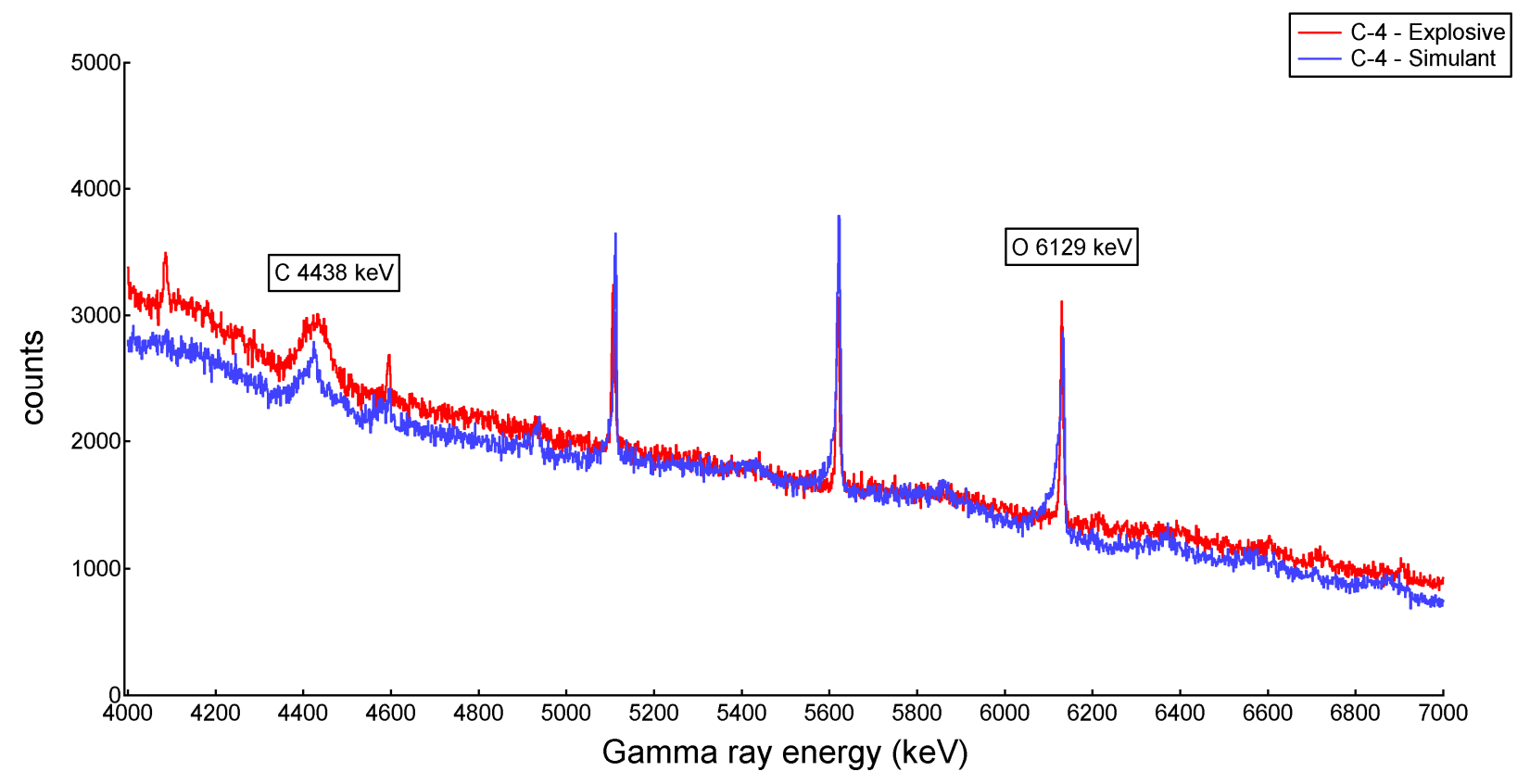

Figure B5. Oxygen region of C-4 explosive and simulant spectra

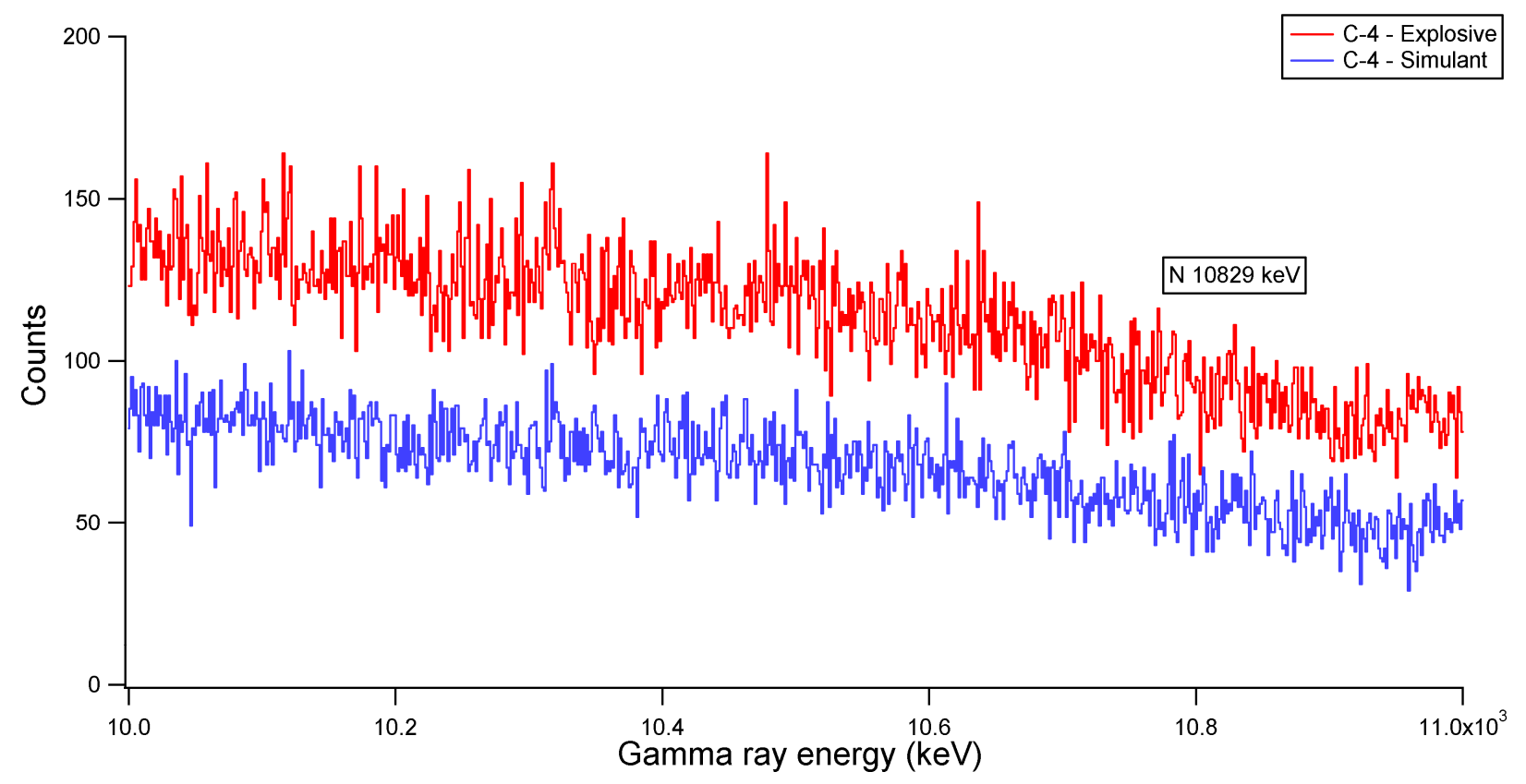


Figure B6. Nitrogen region of C-4 explosive and simulant spectra.

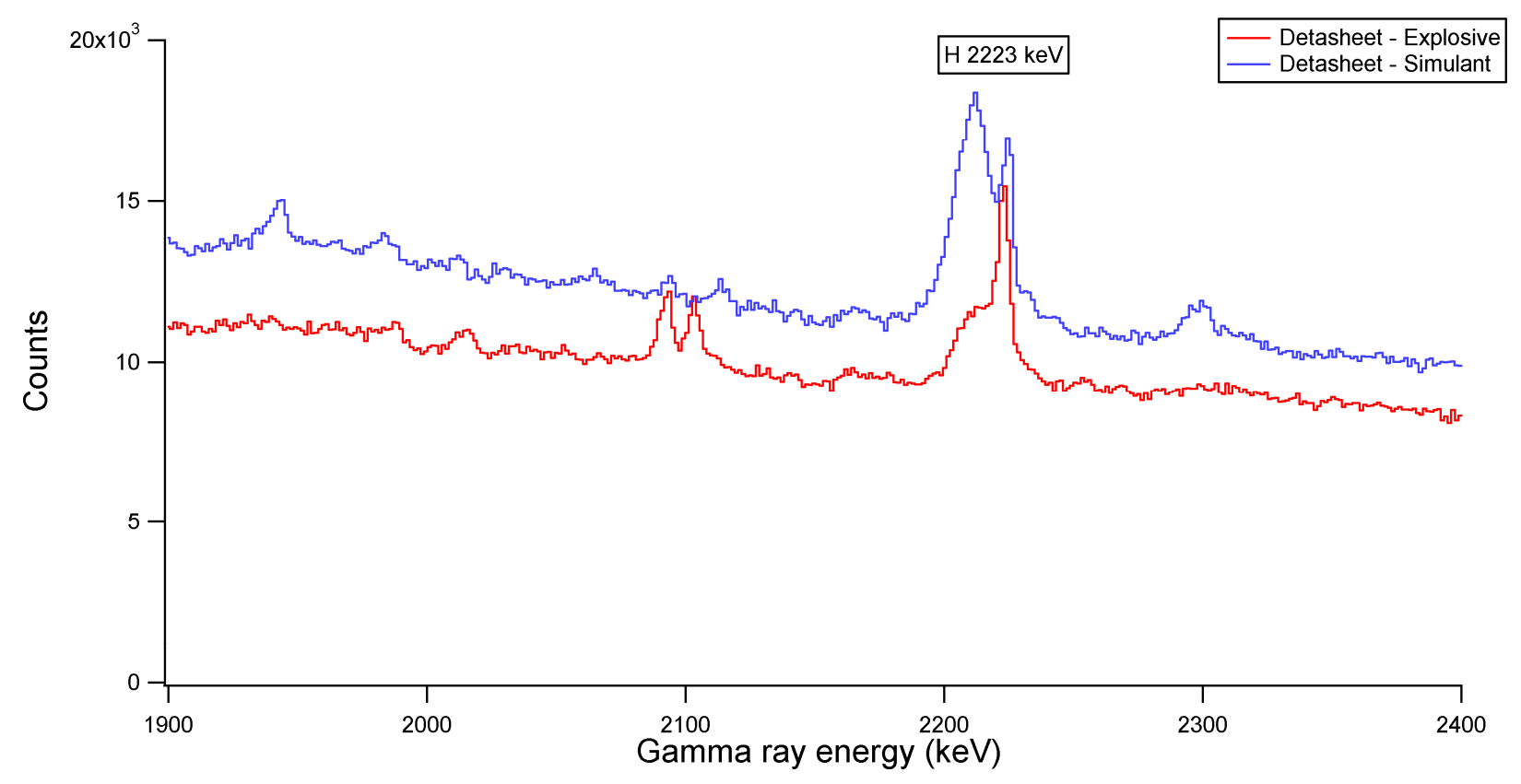

Figure B7. Hydrogen region of Detasheet explosive and simulant spectra.

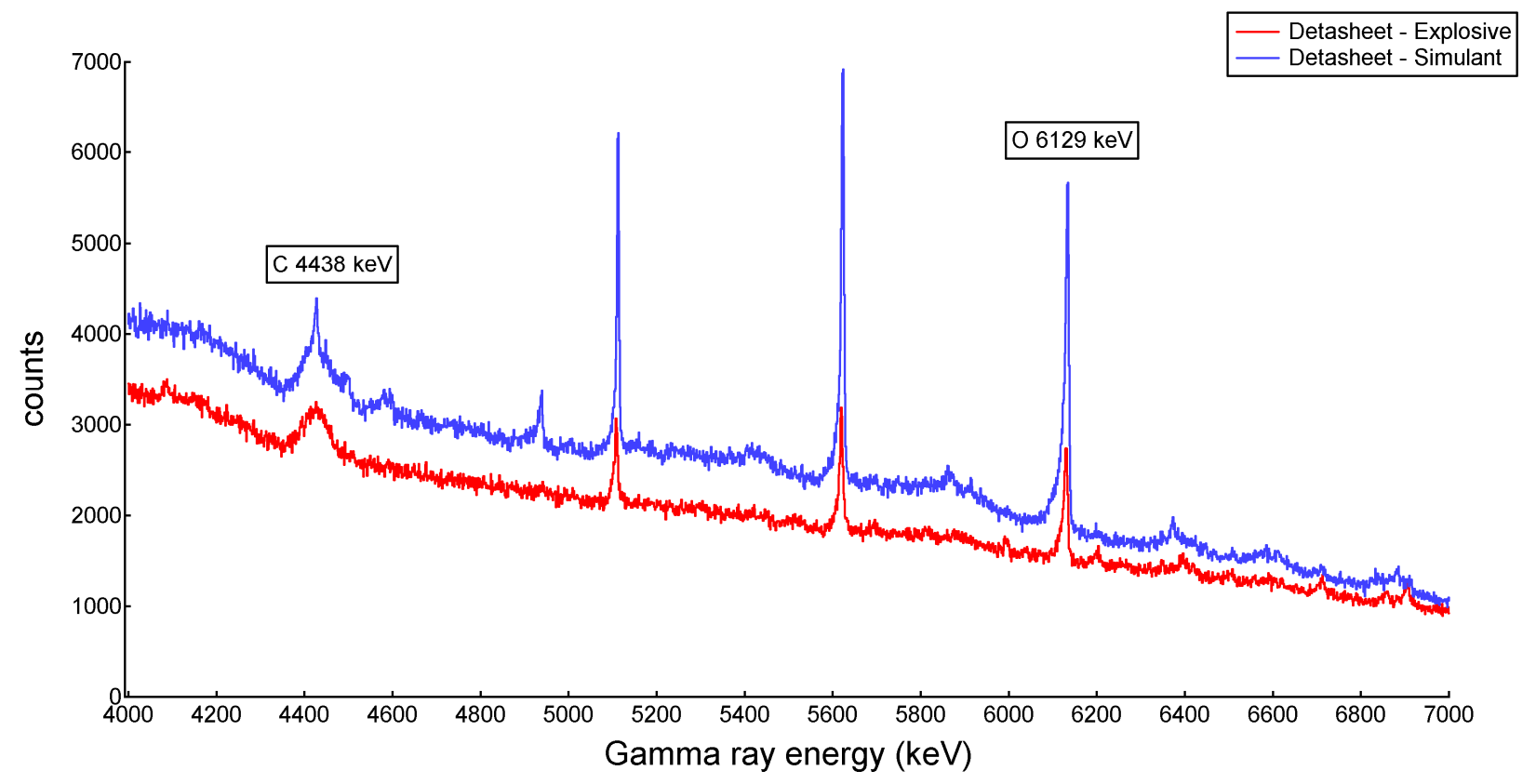

Figure B8. Oxygen region of Detasheet explosive and simulant spectra. 




Figure B9. Nitrogen region of Detasheet explosive and simulant spectra.

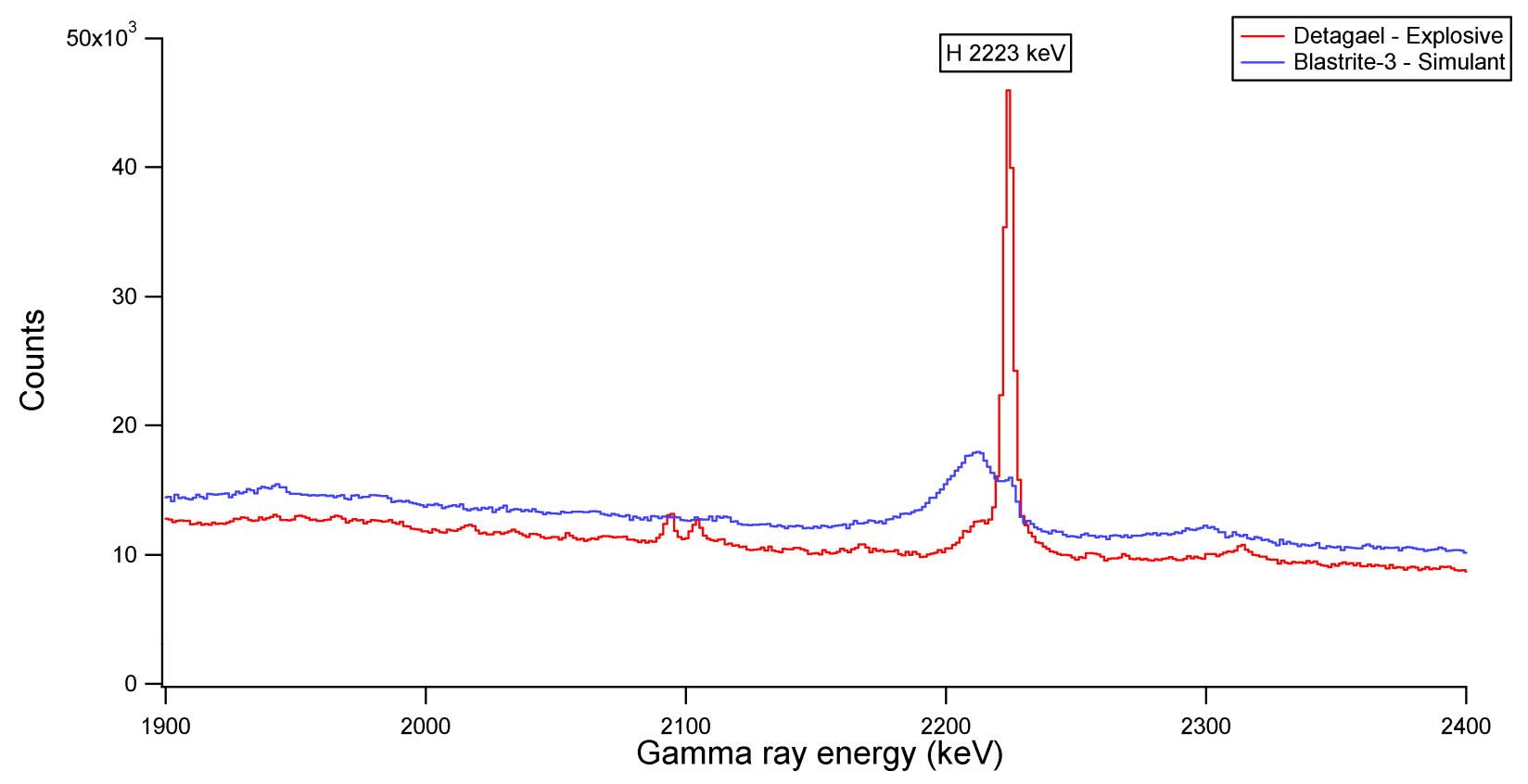

Figure B10. Hydrogen region of Detagel explosive and Blastrite-3 simulant spectra. 


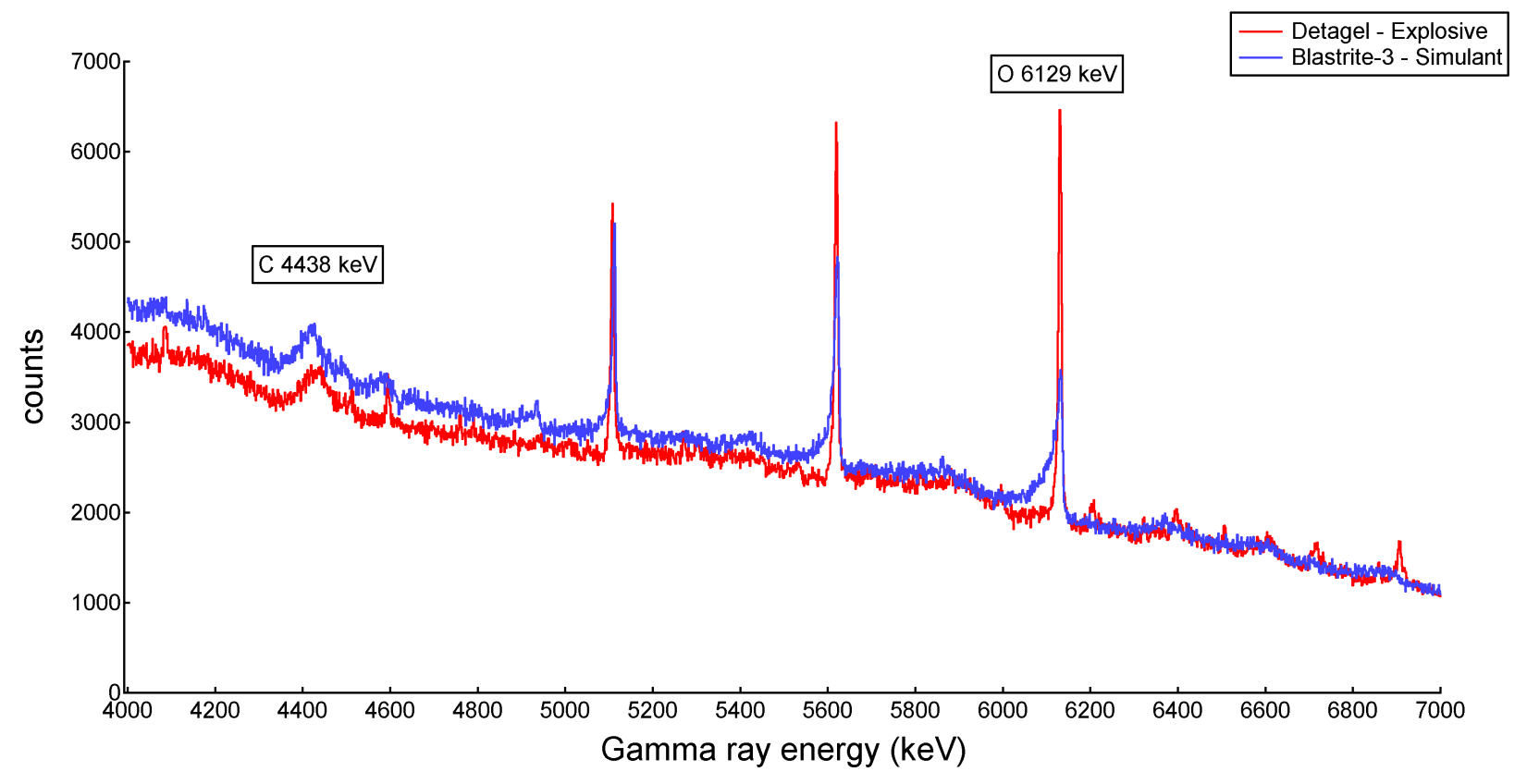

Figure B11. Oxygen region of Detagel explosive and Blastrite-3 simulant spectra.

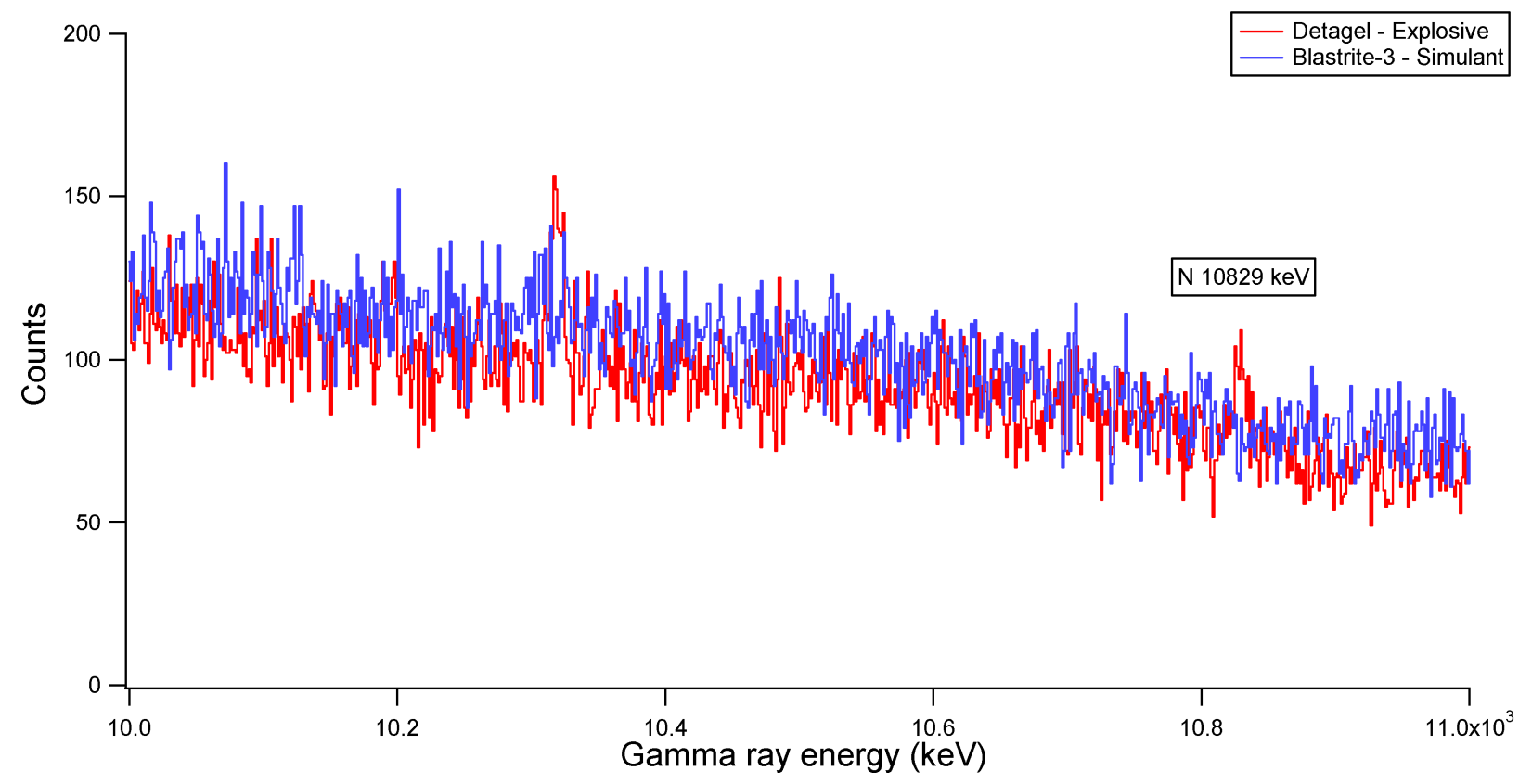

Figure B12. Nitrogen region of Detagel explosive and Blastrite-3 simulant spectra. 


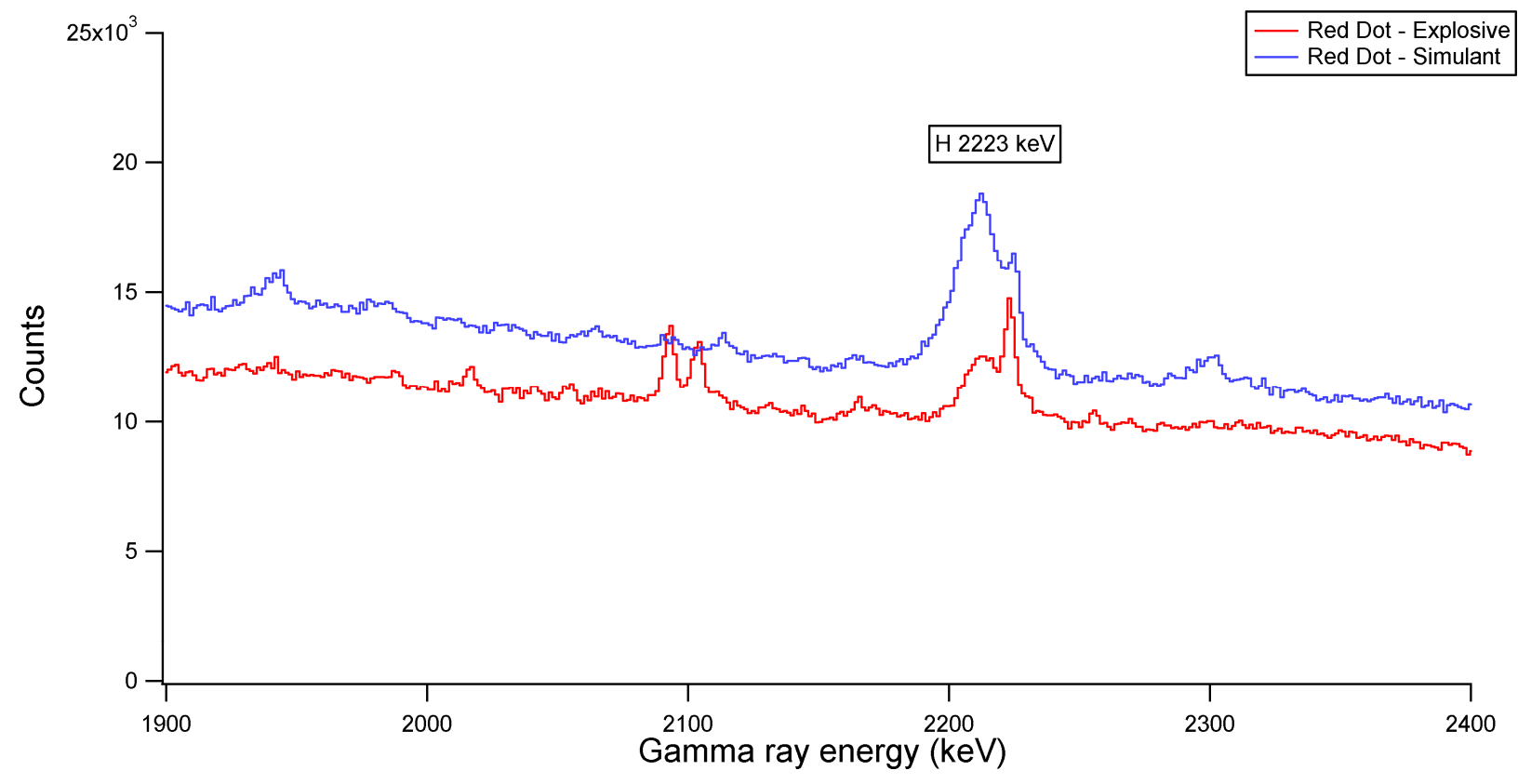

Figure B13. Hydrogen region of Red Dot explosive and simulant spectra.

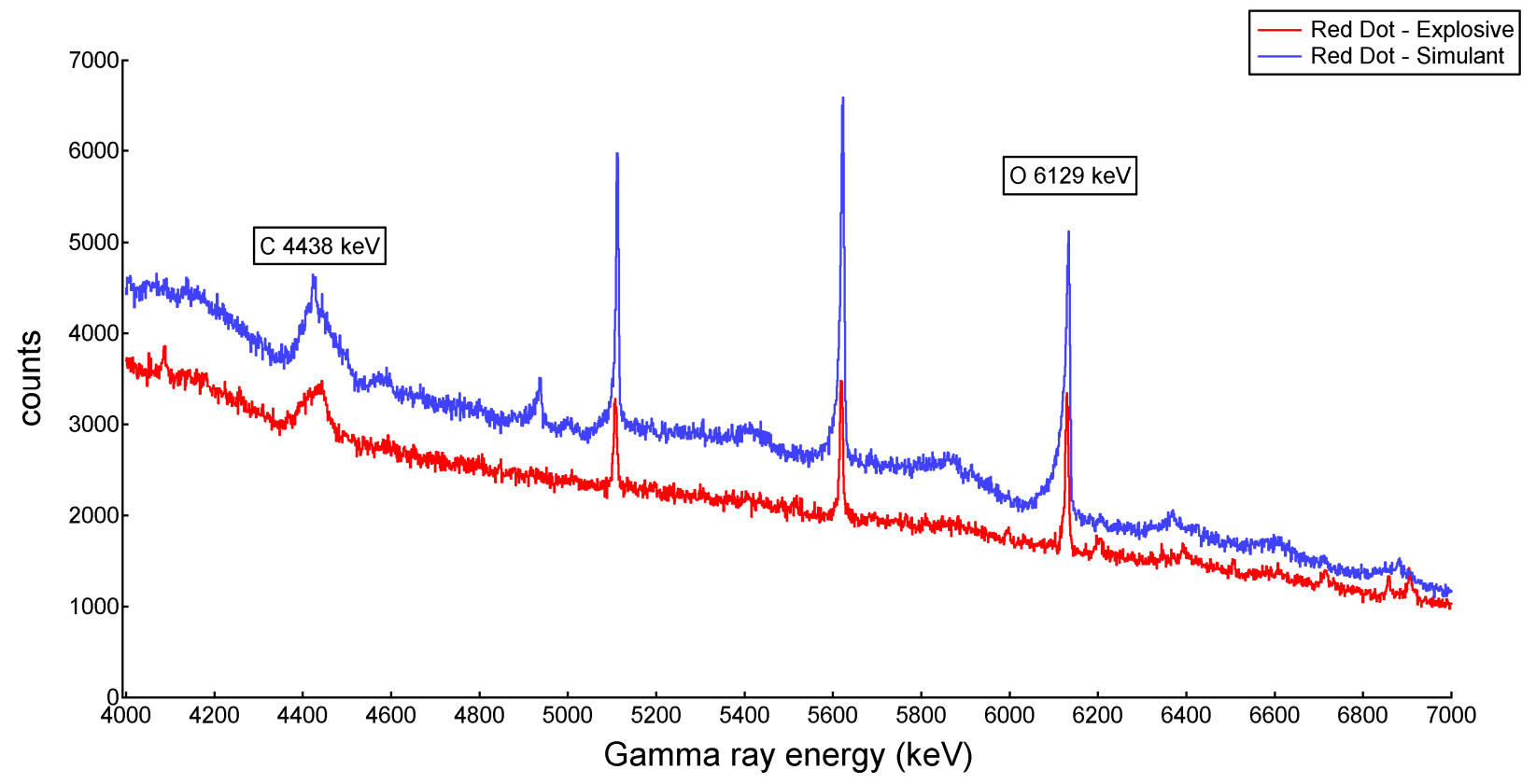

Figure B14. Oxygen region of Red Dot explosive and simulant spectra. 


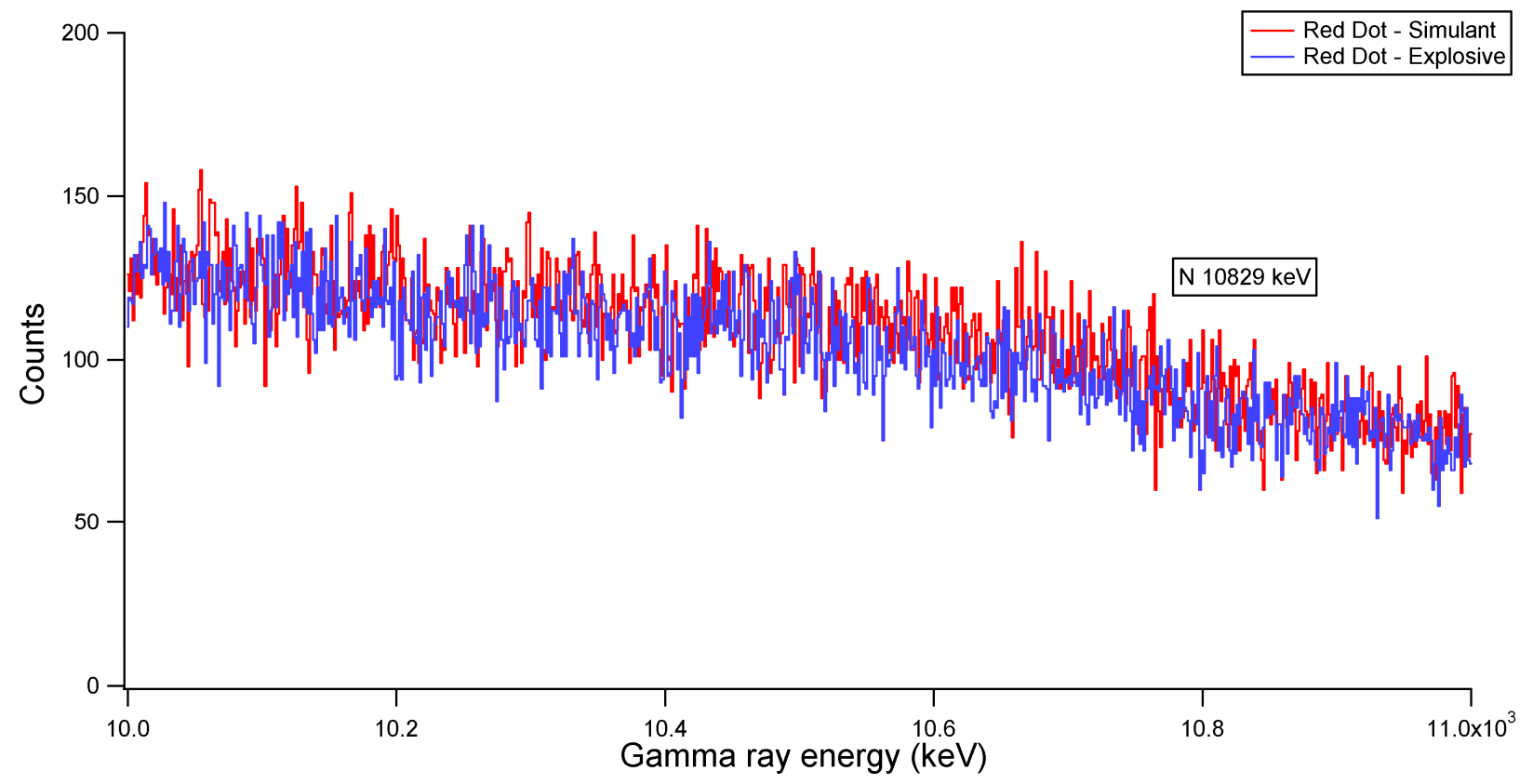

Figure B15. Nitrogen region of Red Dot explosive and simulant spectra.

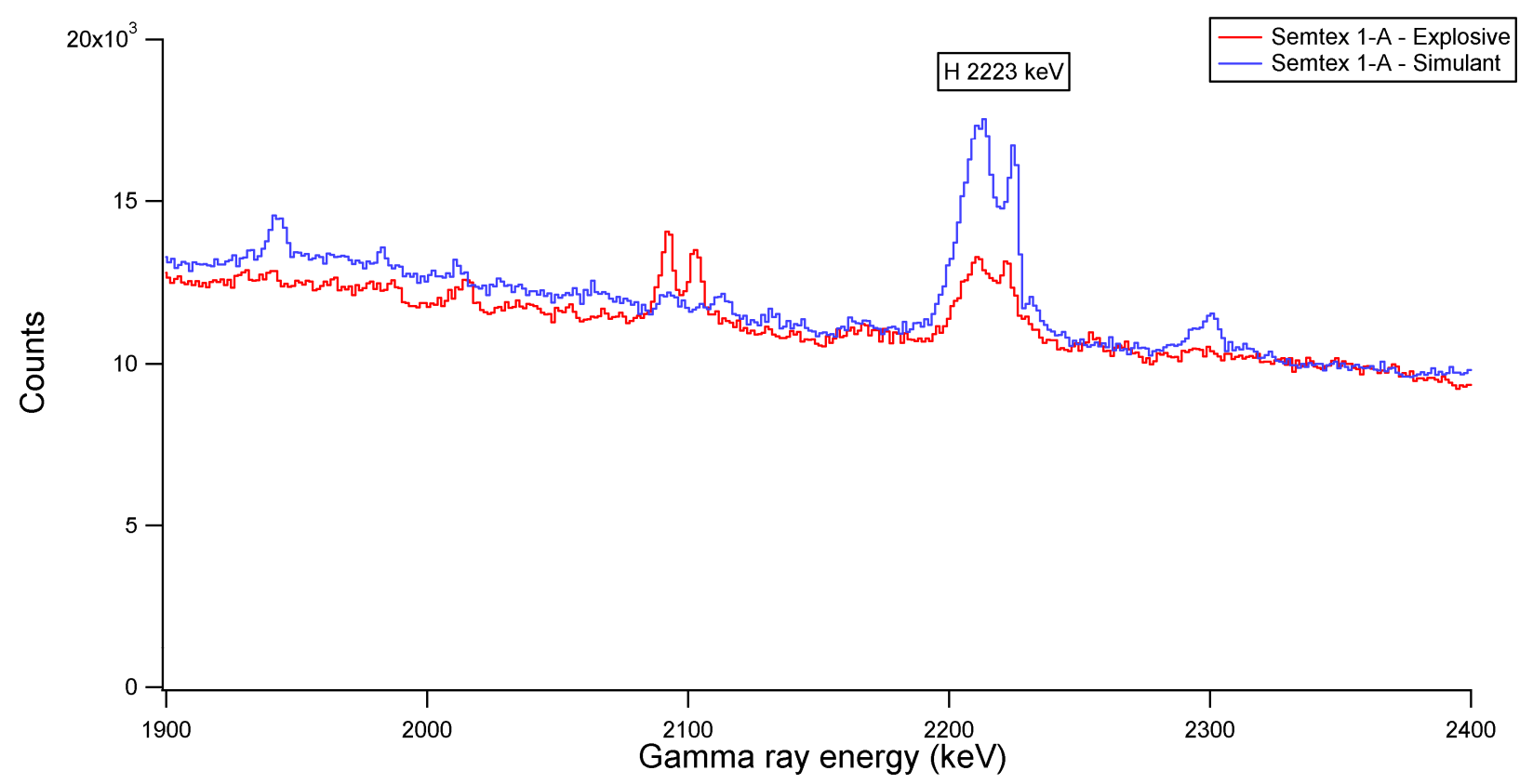

Figure B16. Hydrogen region of Semtex 1-A explosive and simulant spectra. 


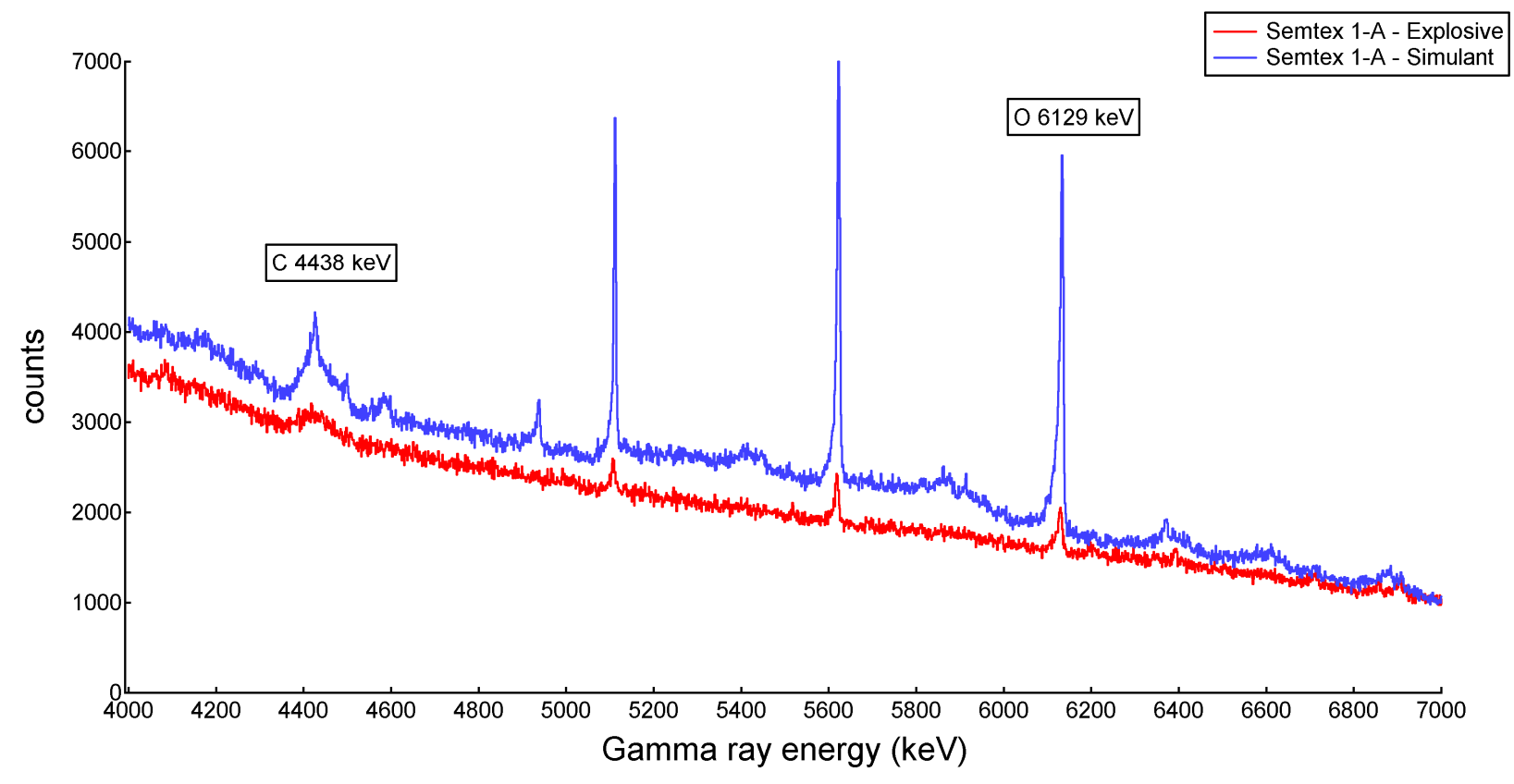

Figure B17. Oxygen region of Semtex 1-A explosive and simulant spectra.

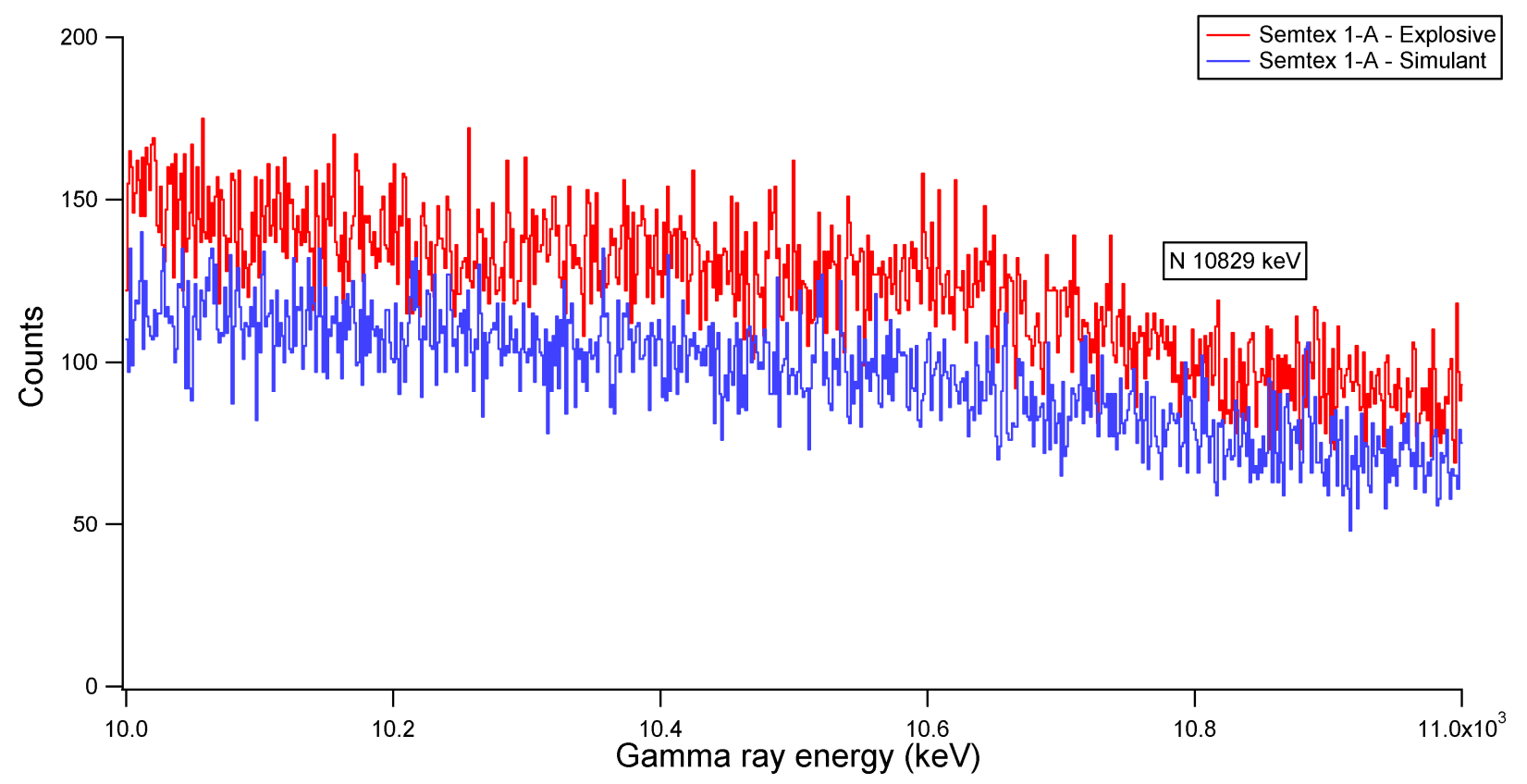

Figure B18. Nitrogen region of Semtex 1-A explosive and simulant spectra. 


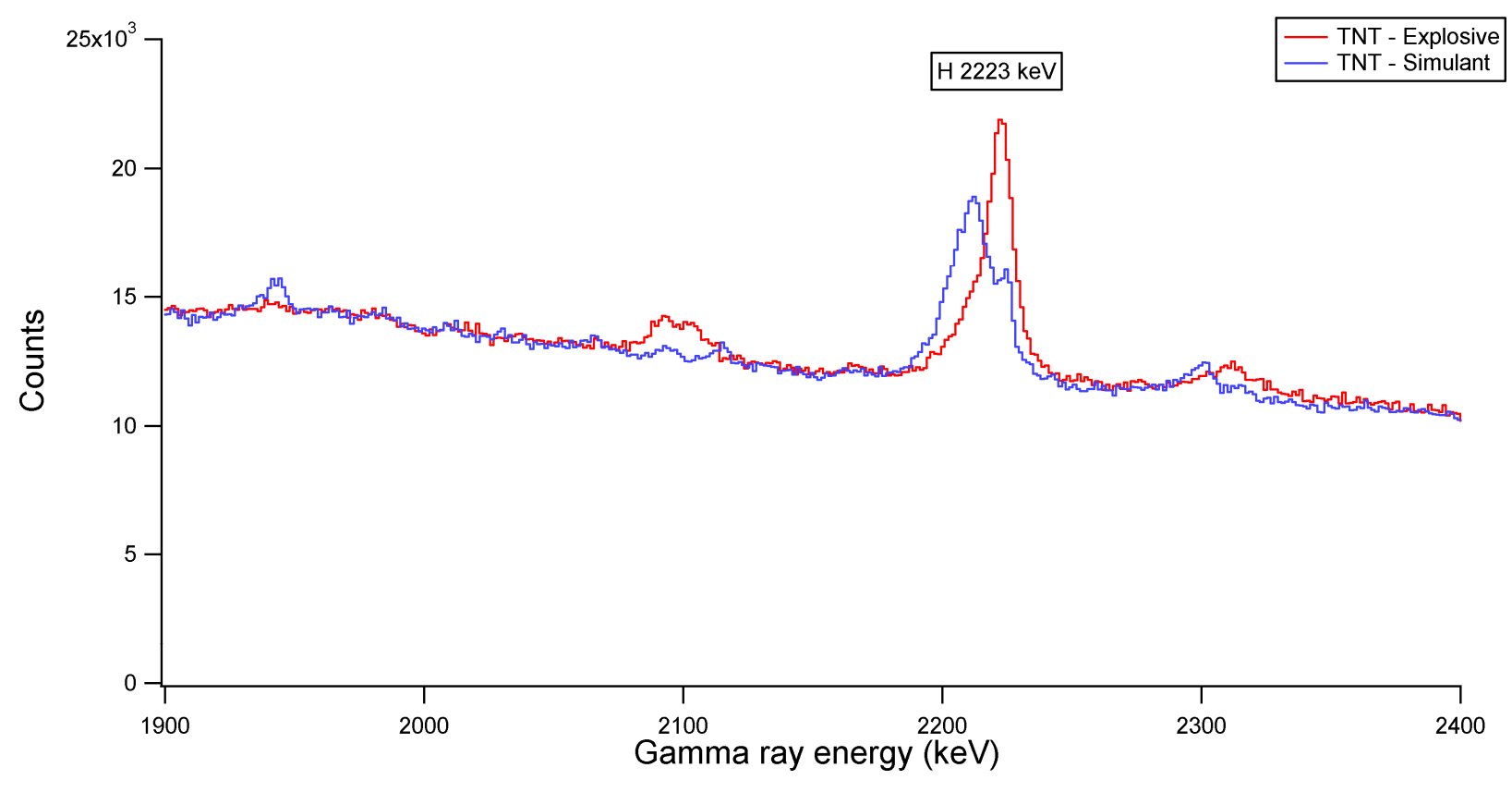

Figure B19. Hydrogen region of TNT explosive and simulant spectra.

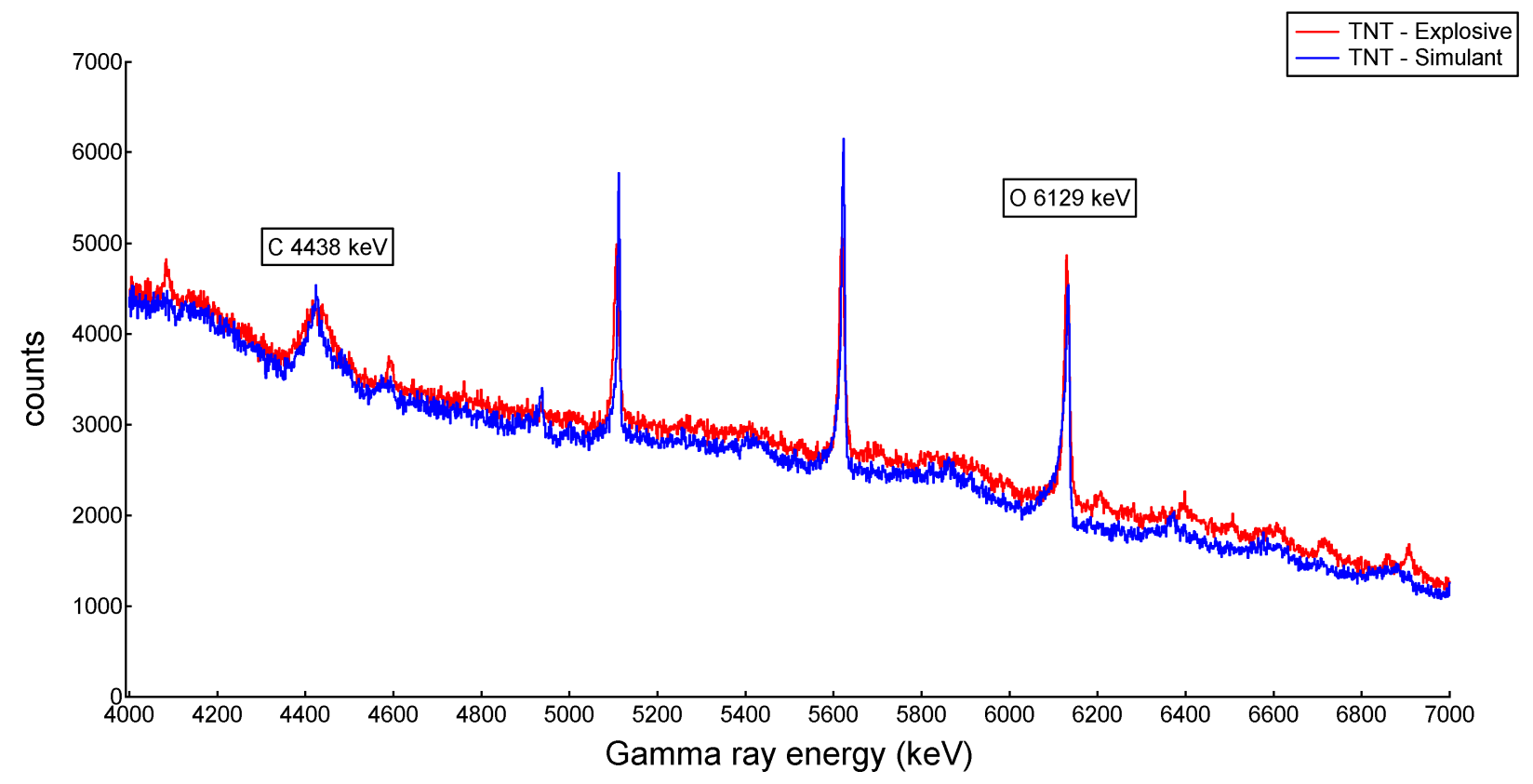

Figure B20. Oxygen region of TNT explosive and simulant spectra. 


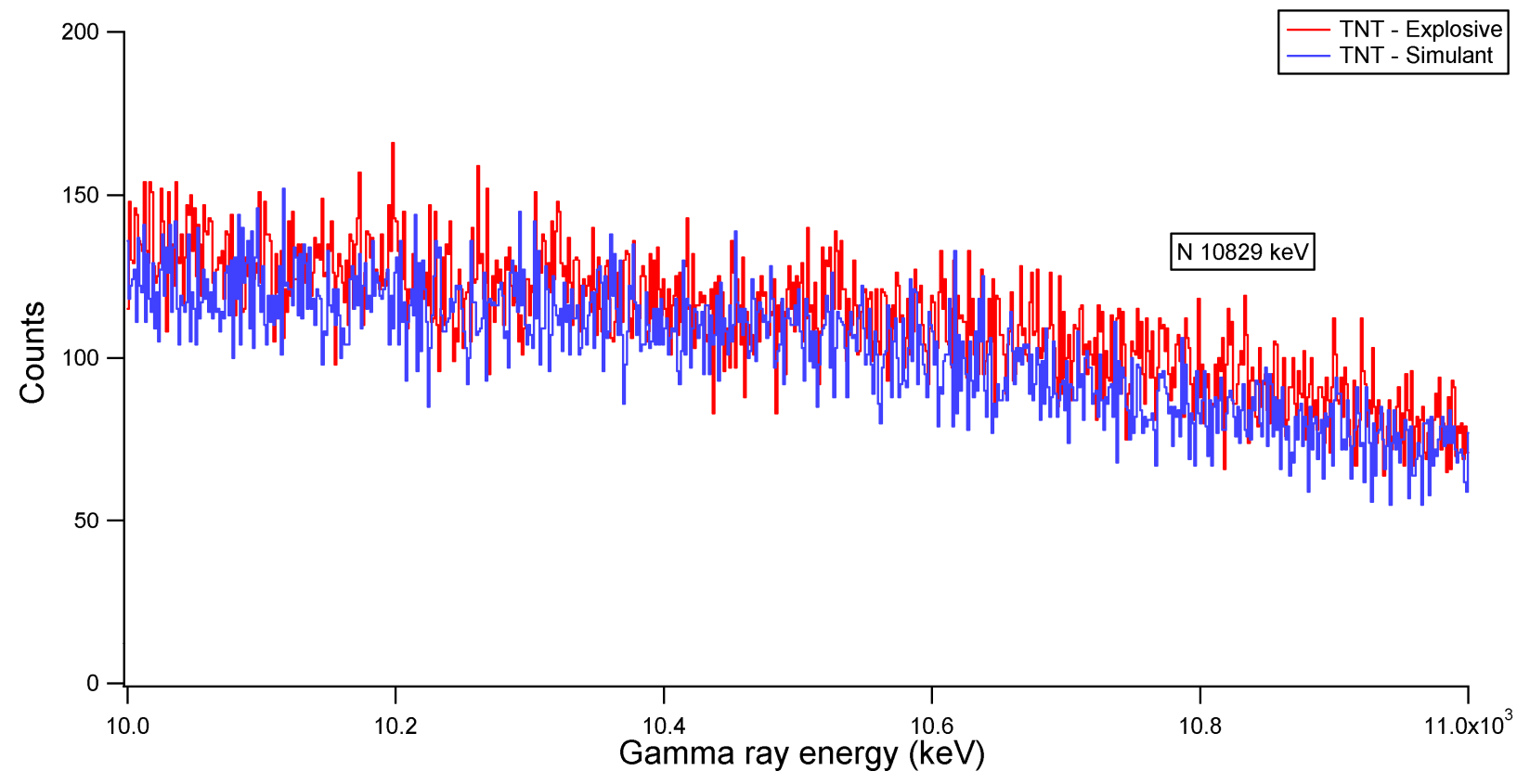

Figure B21. Nitrogen region of TNT explosive and simulant spectra.

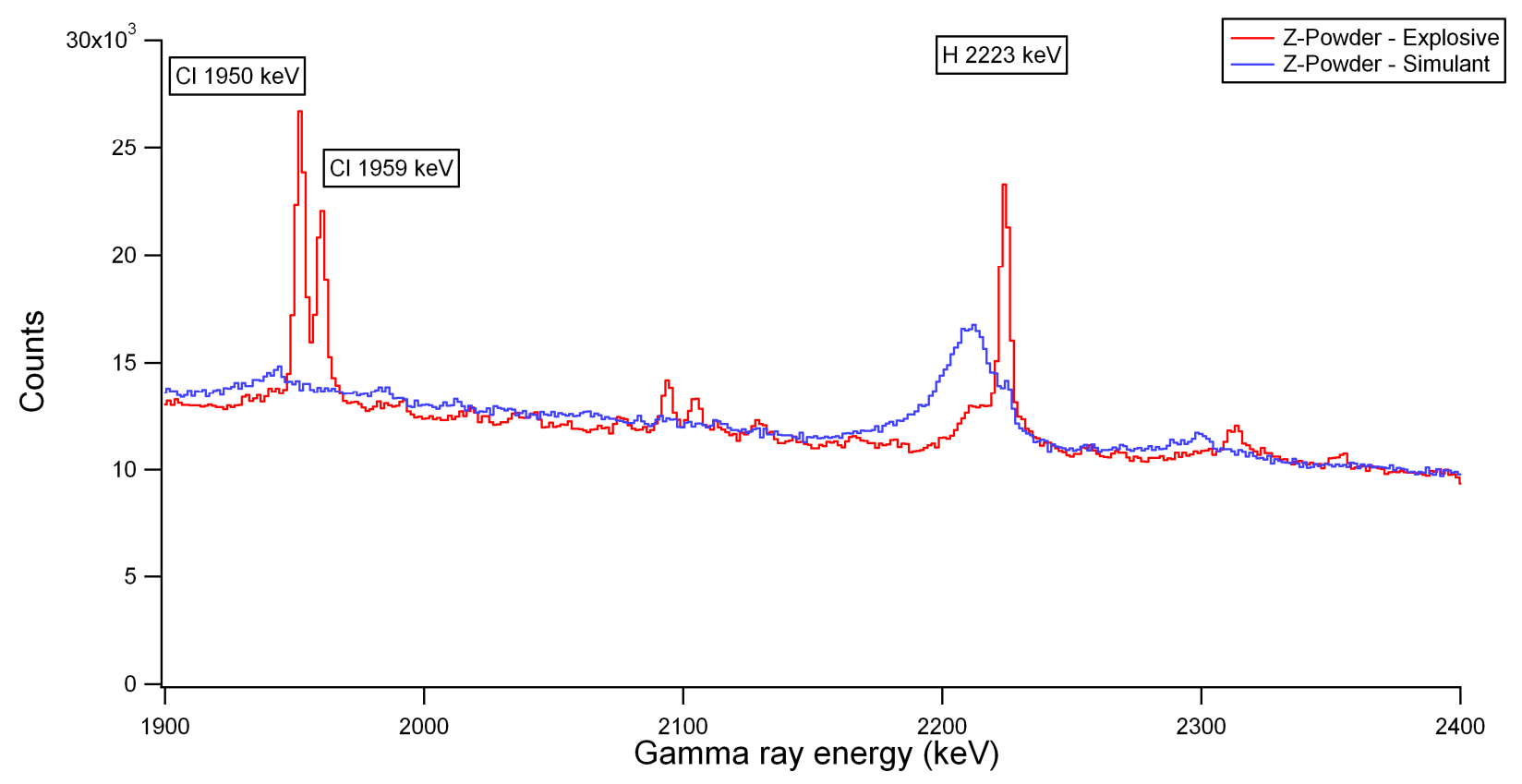

Figure B22. Hydrogen region of Z-Powder explosive and simulant spectra. 


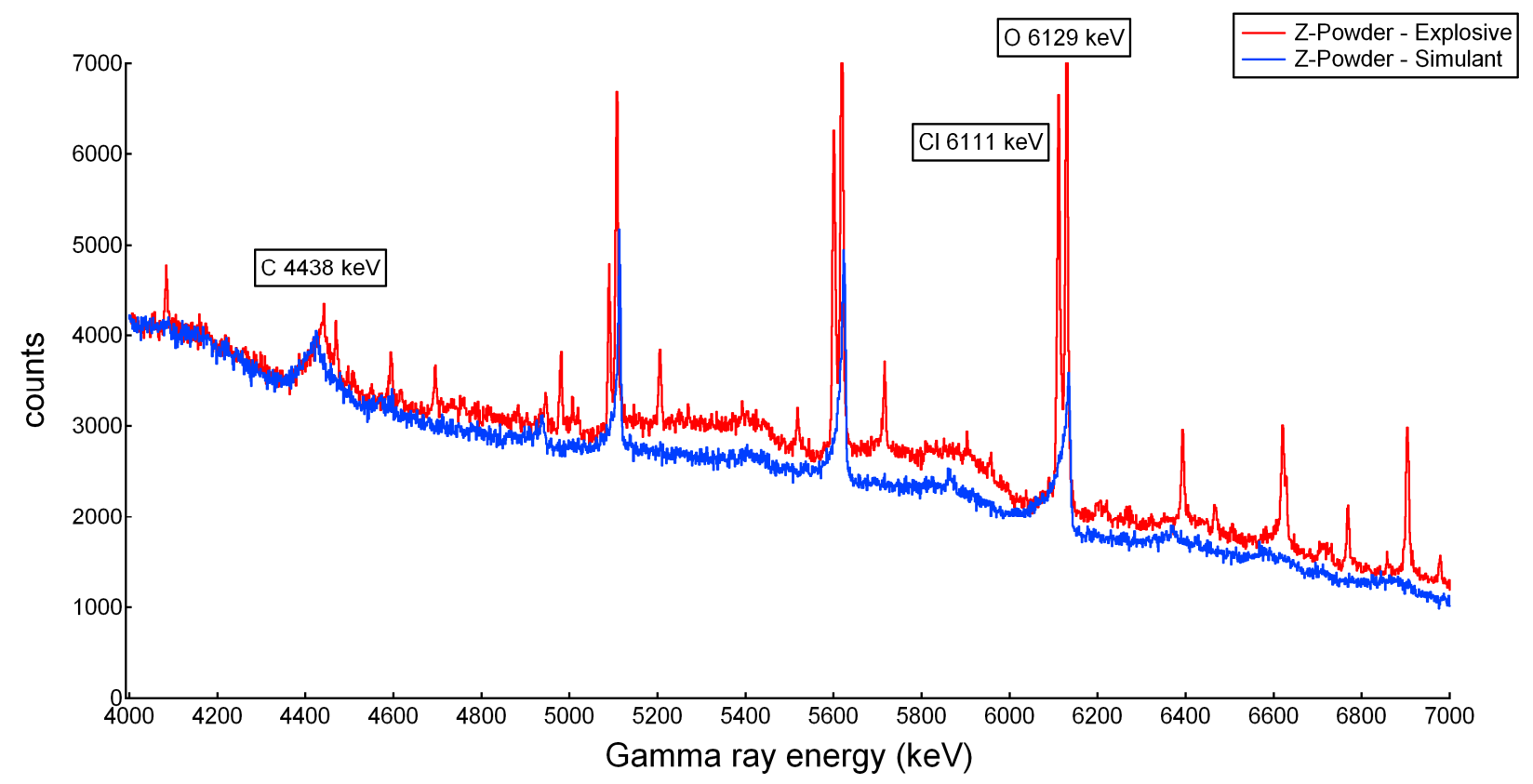

Figure B23. Carbon region of Z-Powder explosive and simulant spectra.



Figure B24. Nitrogen region of Z-Powder explosive and simulant spectra. 